WORKING PAPER

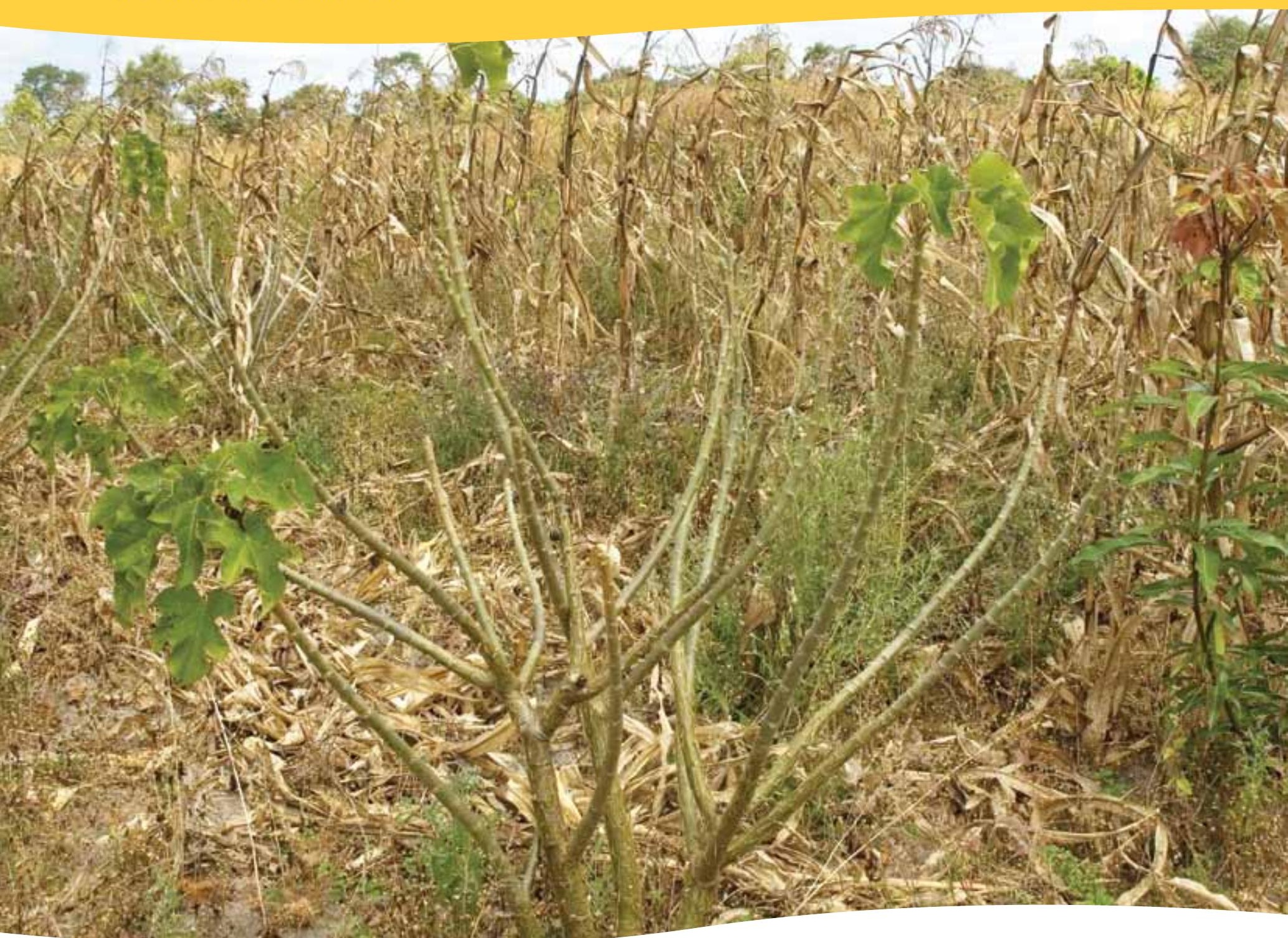

\title{
Analysis of the potential of sustainable forest-based bioenergy for climate change mitigation
}

David Neil Bird

Giuliana Zanchi

Naomi Pena

Petr Havlík

Dorian Frieden

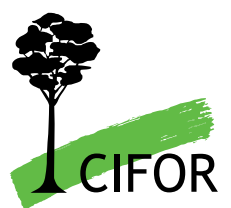





\title{
Analysis of the potential of sustainable forest-based bioenergy for climate change mitigation
}

\author{
David Neil Bird \\ Giuliana Zanchi \\ Naomi Pena \\ Petr Havlík \\ Dorian Frieden
}




\author{
Working Paper 59 \\ (C) 2011 Center for International Forestry Research \\ All rights reserved
}

Bird, N.D., Zanchi, G., Pena, N., Havlík, P. and Frieden, D. 2011 Analysis of the potential of sustainable forest-based bioenergy for climate change mitigation. Working Paper 59. CIFOR, Bogor, Indonesia

Cover photo: Jeff Walker

This paper has been produced with the financial assistance of the European Union, under a project titled, 'Bioenergy, sustainability and trade-offs: Can we avoid deforestation while promoting bioenergy?' The objective of the project is to contribute to sustainable bioenergy development that benefits local people in developing countries, minimises negative impacts on local environments and rural livelihoods, and contributes to global climate change mitigation. The project will achieve this by producing and communicating policy relevant analyses that can inform government, corporate and civil society decision-making related to bioenergy development and its effects on forests and livelihoods. The project is managed by CIFOR and implemented in collaboration with the Council on Scientific and Industrial Research (South Africa), Joanneum Research (Austria), the Universidad Nacional Autónoma de México and the Stockholm Environment Institute. The views expressed herein can in no way be taken to reflect the official opinion of the European Union.

\title{
CIFOR
}

Jl. CIFOR, Situ Gede

Bogor Barat 16115

Indonesia

$\mathrm{T}+62(251) 8622-622$

$\mathrm{F}+62(251) 8622-100$

E cifor@cgiar.org

\section{www.cifor.cgiar.org}

Any views expressed in this publication are those of the authors. They do not necessarily represent the views of CIFOR, the authors' institutions or the financial sponsors of this publication 


\section{Table of contents}

Abbreviations $\quad$ v

Executive summary

1 Introduction 1

1.1 Structure and scope of the working paper 1

2 State-of-the-art estimates on bioenergy potentials 2

3 Land use change emissions including dead wood, litter and soil organic carbon 5

3.1 Methodology 5

$\begin{array}{lll}3.2 \text { Results } & 10\end{array}$

3.3 Sensitivity to DWLSOC assumptions 11

4 Emissions from biofuels compared to emissions from fossil fuels 13

4.1 Sensitivity to Life Cycle Assessment assumptions 14

5 Accounting using alternative systems 15

5.1 Partial participation 18

6 Conclusions 21

References 23

Appendices 25

1 Sensitivity to land use change scenarios 25

2 Emission factors for life-cycle emissions from biofuels and fossil fuels 26

3 Combustion emission factors for biofuels and fossil fuels 26 


\section{List of figures and tables}

\section{Figures}

1 Ranges of biomass potential of different biomass sources and years 2

2 Regional distribution of reported global bioenergy potentials 3

3 Estimates of emissions from land use change by 2020 due to biofuels from various studies 6

4 Estimated cumulative afforestation and deforestation and net forest area changes caused by future biofuel production, 2000-2030, baseline scenario, agriland option

5 Estimated cumulative net emissions from living biomass due to land use change caused by biofuels, 2000-2030, baseline scenario, agriland option

6 Map of the ecological zones from IPCC 2006 (A) and map of the regions of the GLOBIOM model (B)

7 Stand-based model emissions from DWLSOC: example of deforestation in Latin America

8 Estimated cumulative emissions from all biomass due to land use change caused by biofuels, 2000-2030, baseline scenario, agriland option

9 Contribution of different carbon pools to overall emissions from land use change when low (A) or high (B) default values for dead wood, litter and soil are selected, baseline scenario, agriland option

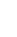
6

10 Cumulative emissions from fossil fuels and biofuels without DWLSOC, baseline scenario, agriland option

11 Cumulative emissions from fossil fuels and biofuels with DWLSOC, baseline scenario, agriland option

12 Sensitivity of cumulative emissions from fossil fuels and biofuels (with DWLSOC) to variability in LCA emission factors, baseline scenario, agriland option

13 Emissions by region under different accounting systems. baseline scenario, agriland option

14 Sensitivity of cumulative emissions from fossil fuels and biofuels with DWLSOC to different scenarios

\section{Tables}

1 Total cumulative emissions caused by biofuels in 2030 by region under different accounting systems

2 Cumulative emissions from land use change caused by biofuel production 19

3 Cumulative emissions caused by biofuels in 2030 by region under different accounting systems 


\section{Abbreviations}

$A B C S$

dLUC

DWLSOC

GHG

IEA

iLUC

IPCC

LCA

LUC

POUR

REDD

UNFCCC

2006 IPCC Guidelines

EU Renewable Energy Directive

$\mathrm{SOC}$
Aboveground and belowground biomass carbon stock

Direct land use change

Dead wood, litter and soil organic carbon-the three carbon pools of non-living biomass in an ecosystem

Greenhouse gas

International Energy Agency

Indirect land use change

Intergovernmental Panel on Climate Change

Life cycle assessment

Land use change

Point of uptake and release accounting approach

Reducing emissions from deforestation and forest degradation

United Nations Framework Convention on Climate Change

2006 IPCC Guidelines for National Greenhouse Gas Inventories

Directive 2009/28/EC of the European Parliament and of the Council

of 23 April 2009 on the promotion of the use of energy from renewable sources and amending and subsequently repealing

Directives 2001/77/EC and 2003/30/EC

Soil orgranic carbon 


\section{Executive summary}

This paper is part of the Europe Aid Project 'Bioenergy, sustainability and trade-offs: Can we avoid deforestation while promoting bioenergy?' The purpose of the research was to create an improved analysis of the potential of sustainable forest-based bioenergy for climate change mitigation.

To do so, the authors have improved on an existing estimate of land use change and greenhouse gas emissions from biofuels from Havlík et al. (2011). That study assessed all land use changes (direct and indirect) that will occur in the future as a result of including biofuels in the market demand for land. The land use changes (LUCs) caused by biofuels, and the greenhouse gas emissions connected to these changes, are estimated in the study by projecting land use changes under scenarios that include biofuels (first generation, second generation, or a mixture) and a no-biofuels scenario. The impact of biofuels in terms of land use change emissions is assessed as the difference between biofuel scenarios and non-biofuel scenario.

This paper improves the estimates from Havlík et al. by:

- Adding emissions from changes of dead wood, litter and soil organic carbon (DWLSOC) to the emissions estimate for live biomass;

- Adding a sensitivity analysis of emissions to both the assumed DWLSOC carbon stocks and life cycle assessment of the non-LUC emissions;

- Investigating different options for accounting for the emissions from biofuels; and

- Investigating the timing of emissions from biofuels in comparison to the emissions from fossil fuels by presenting time series rather than cumulative emissions over a given time frame.

It is clear from Havlík et al. that the emissions from biofuels are dominated by the assumed technology adoption scenario. The Havlík study found that the emissions from biofuels can vary by more than an order of magnitude depending on assumptions about the adoption of technology to create liquid biofuels from cellulosic material (second generation biofuels). This conclusion is beyond the scope of our analysis, but we restate it here so that our conclusions can be viewed with the right perspective.

Nevertheless, including DWLSOC in the estimate of emissions from the adoption of biofuels is important. The significance is directly related to the amount of deforestation predicted by the LUC model. We found that including DWLSOC increased greenhouse gas emissions from biofuels by $21 \%$. This result is relatively sensitive to the parameters used to describe the DWLSOC dynamics, primarily because the parameters are not well known (usually $\pm 50 \%$ ). On the other hand, even though emissions from the nonLUC component are quite substantial—about 25\% of total emissions - the non-LUC parameters are more accurate than the DWLSOC parameters. The total cumulative emissions are less sensitive to this uncertainty.

On the topic of accounting approaches, we reiterate that the approach currently adopted by the IPCC and international community does not allocate emissions from the combustion of bioenergy in the energy sector. Rather, emissions from bioenergy are included in the land use sector if the bioenergy causes decreases of carbon stocks. As a result, this approach:

- Does not properly allocate emissions to the region in which they occur; and

- Captures the true emissions from the use of biofuels very poorly, if only Annex I countries participate in an accounting target.

There are alternatives such as 'point-of-uptake and release', which perform these two tasks better.

Perhaps our most striking result is that emissions from the adoption of biofuels in the Havlík model 'baseline' scenario (60\% first generation, $40 \%$ second generation) are more than the emissions from the fossil fuels that they displace, even though bioenergy 
is carbon neutral in the long term. This result occurs only if one analyses the timing of emissions and not the life-cycle emissions. It occurs because every addition of biofuels causes an associated emission with a 'payback' period. If the growth of biofuel consumption is large, the year-over-year emissions from biofuels may always be more than the fossil fuels they are intended to displace. 



\section{Introduction}

Current climate mitigation policies are likely to become a strong driver of increased demand for renewable energy sources and particularly for bioenergy. Therefore, it is becoming more and more important to assess the potential amount of biomass that will be available for future energy production and the costs, in terms of greenhouse gas (GHG) emissions, connected to extraction of these potentials. The estimate of emissions produced by different bioenergy sources is important for evaluating the advantages of biomass-based energy compared to fossil fuel use. This allows promotion of energy sources that are the most advantageous for climate mitigation.

During production of bioenergy, different types of GHG emissions are released in the atmosphere. These emissions are produced at different stages of the bioenergy life cycle by different processes (production, conversion, distribution, consumption). One of the most uncertain sources of GHG emissions from bioenergy is land use change (LUC) that occurs as a result of including biofuels in the market demand for land. For instance, when bioenergy comes from dedicated annual or permanent crops, land that was previously used for other purposes is converted to bioenergy production. This is known as direct land use change (dLUC). As a consequence, we can expect land use changes to occur globally when the demand for bioenergy increases. When land use is changed, carbon stocks in living biomass, dead organic matter and soil also change. Depending on the type of land use conversion, carbon might be sequestered from or released to the atmosphere.

This dLUC can also cause indirect land use changes (iLUC) as economic forces adjust to changes in demand and supply of biomass for food and fibre. The amount and location of iLUC is difficult to predict because it depends on many factors, such as competition with other uses (e.g. food production) and market and policy scenarios. Nevertheless, models have been developed that can assess the impact of different bioenergy use projections on land use, and these are continuously improved.

A further step is calculation of the carbon stock changes, i.e. the carbon emissions, connected to the land use changes. The number of carbon pools included in the assessment is one of the factors that can strongly affect the final results. The period during which the carbon stock changes occur can also affect the estimates, which are usually done over certain time horizons.

\subsection{Structure and scope of the working paper}

This paper aims to provide an improved analysis of the capability of sustainable forest-based bioenergy (particularly biofuels) to mitigate climate change. For this purpose, we first present a short overview of existing estimates of bioenergy potentials and emissions connected to these potentials to help identify assessment gaps. As a second step, starting from one existing study, we provide improved estimates of emissions from land use change caused by biofuels by:

- Including carbon pools that were previously neglected (dead wood, litter and soil); and

- Showing the development over time of emissions from biofuels and comparing these time series to fossil-fuel emissions.

Sensitivity tests are performed to identify factors that significantly affect the results.

As a final step, we use the improved estimates to show how emissions from bioenergy can be accounted for under different accounting systemsin particular those that differ from the IPCC—and how this can affect the GHG benefits and costs attributed to bioenergy. 


\section{State-of-the-art estimates on bioenergy potentials}

Results and assumptions made in available global biomass potential assessments vary significantly from study to study. One recent study compared the results from 19 bioenergy potential estimates (Thrän et al. 2010). It shows that biomass potential estimates differ in the definition of potential that is considered (theoretical, technical, economical or implementable), the time horizon, the biomass sources included and the geographical resolution. Most of the analysed studies estimated the technical potential, but often studies do not clearly define which potential is analysed and which biomass sources are included in each biomass category. As a consequence, different types of potential have to be compared.

Among the analysed studies, the potential from energy crops is the most uncertain (Figure 1). The amount of biomass and energy from energy crops depends heavily on future demand for arable land for food production and therefore on the competition between different uses of arable land (energy versus food production). The most important factors influencing the demand for area allocated to food production are population growth trends, changes in food consumption patterns and increase of crop yields.

The potential from crop residues varies less among different studies, probably because the competition with food production has a smaller influence on this source. Concerning forest (woody) biomass, definitions of forest residues are the most inconsistent for producing reliable estimates. This is because some studies include thinning and logging residues, industrial production processes and waste, while others include the annual forest increment as well. Due to the different definitions, the studies show high variability of assessment of energy that can be produced for this source of biomass (from 0 to 150 $\mathrm{EJ} \mathrm{yr}^{-1}$ in 2050).

Thrän et al. also summarise the regional distribution of bioenergy potentials by reporting the figures from six studies that included regional results (Figure 2). The review shows that developing countries will play

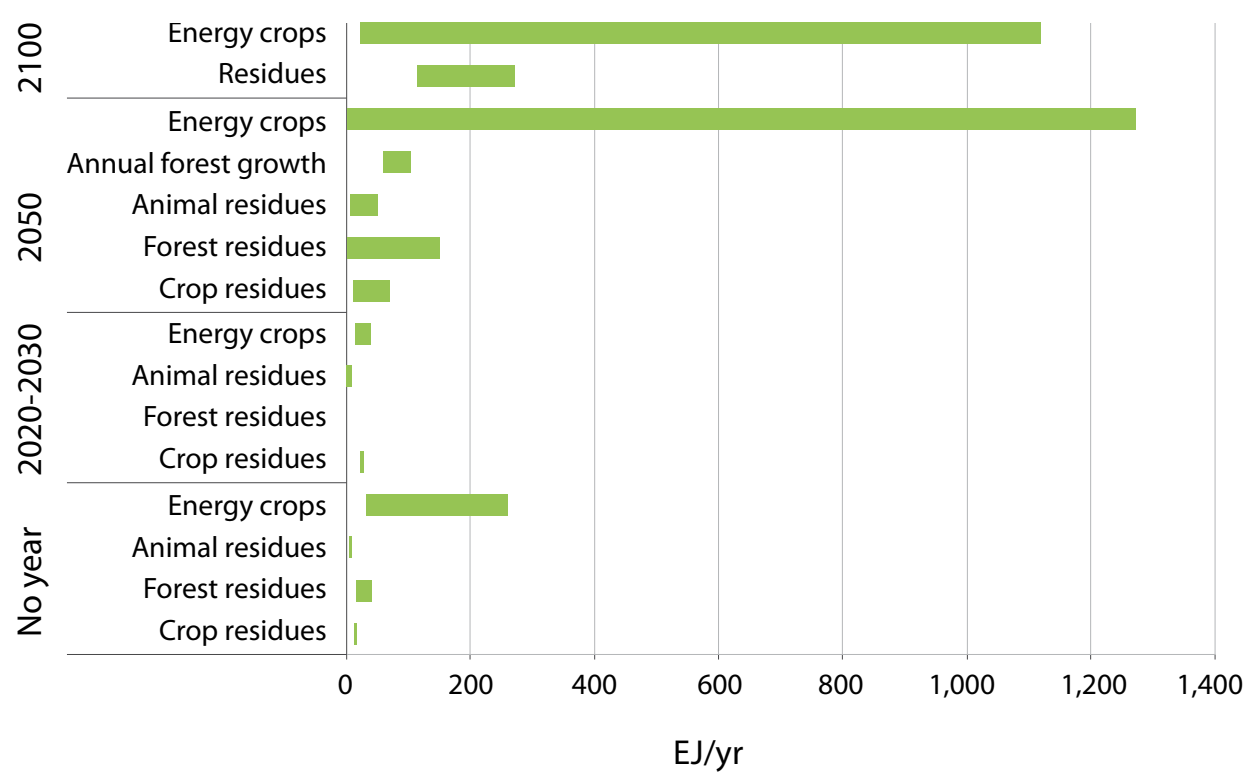

Figure 1. Ranges of biomass potential of different biomass sources and years Source: Thrän et al. (2010) 
a major role in bioenergy production in the future. However, the potentials are significantly influenced by the scarce data available and unstable political situations in these countries.

The study by Thrän et al. also provides a new assessment of technical potential from energy crops under three scenarios. The estimates include only non-food crops (silage of green fodder and grass, short-rotation coppices and hay) on agricultural land; degraded land is excluded.

The three scenarios are:

1. A business-as-usual development of food demand and cropland area that includes a constant annual deforestation rate of $0.24 \%$ of exisiting forest land;

2. A sustainable land use scenario, in which fallow land is progressively converted to crop production and deforestation is not allowed; and

3. An environment and health scenario, in which, in addition to the conditions in sustainable land use, a decrease of crop productivity is included (e.g. for increased organic farming) that is compensated by a decrease of food consumption in countries with high intake rates.
The study estimates that the bioenergy potential from crops in 2050 ranges between $16 \mathrm{EJ}$ in the sustainable land use scenario and $96 \mathrm{EJ}$ in the business as usual scenario. The environment and health scenario provides intermediate results of about $40 \mathrm{EJ}$ in 2050.

Biomass potential studies focus on the amount of available biomass from different sources (dedicated crops, residues, etc.) and therefore on bioenergy that will be produced globally at a certain point in time. Little information is usually provided in these studies on the emissions released in the atmosphere when land use is changed to produce bioenergy. These emissions affect the GHG profile of bioenergy and therefore its contribution to climate mitigation.

A recent study by Havlík et al. (2011) reports information on global deforestation and other land use changes caused by cropland expansion driven by food and bioenergy production under different biofuel scenarios and calculates land use change emissions from the loss of living biomass due to deforestation. The land use change emissions caused by biofuels are estimated in the study by projecting land use changes under scenarios that

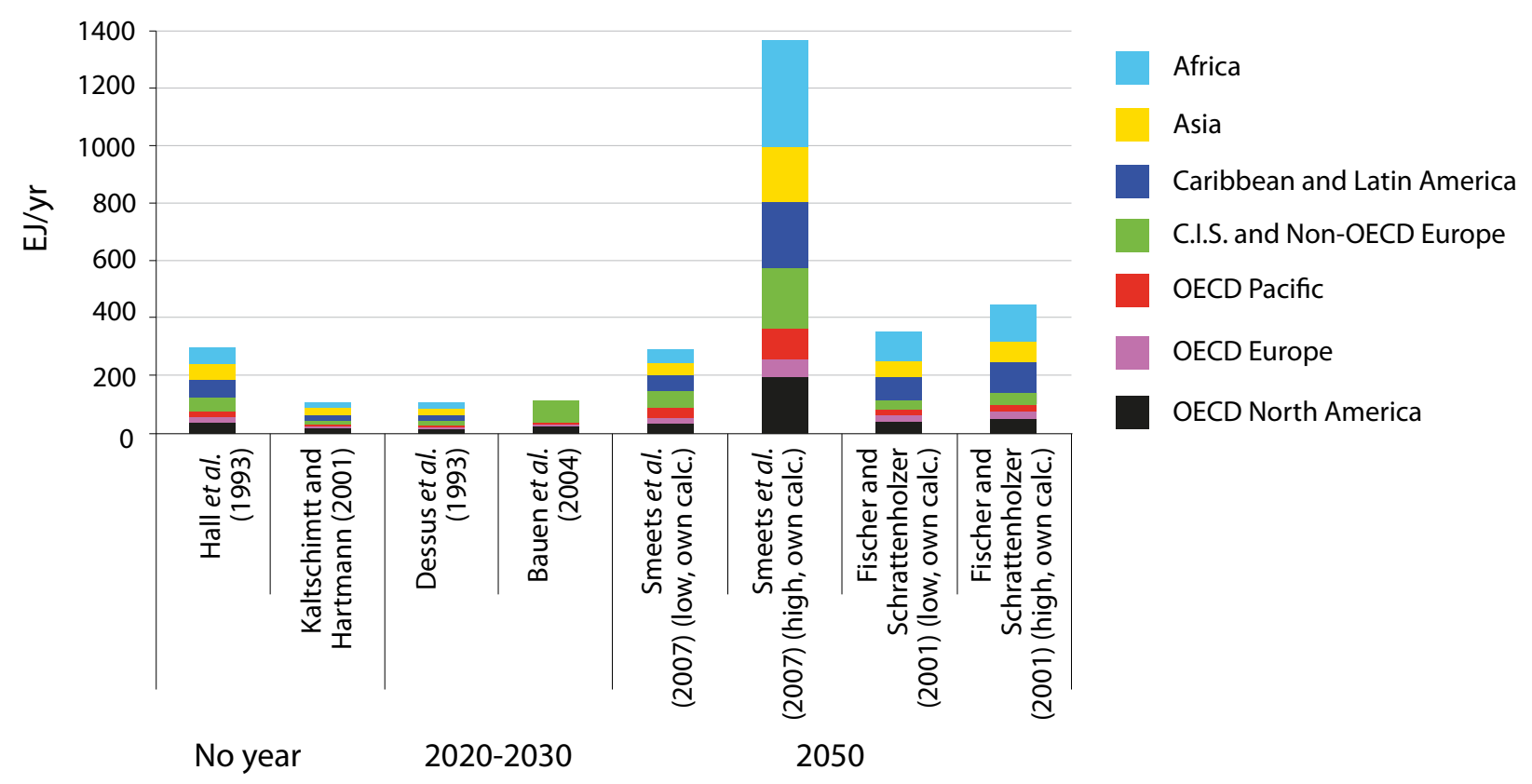

Figure 2. Regional distribution of reported global bioenergy potentials

Source: Thrän et al. (2010) 
include biofuels (first generation, second generation or a mixture) and under a no-biofuels scenario. The impact of biofuels, in terms of land use change emissions, is assessed as the difference between biofuel scenarios and non-biofuel scenarios.

Therefore, the study explores some of the consequences of using biofuels in the future in terms of losses or gains of carbon stocks in the ecosystem. A general guide to calculating emissions from land use conversions has recently been released by the Joint Research Centre (Carré et al. 2010). The methodology provides guidance for estimating GHG emissions in soil and biomass resulting from land use changes, based on a Tier 1 approach of the 2006 IPCC Guidelines for National Greenhouse Gas Inventories (IPCC 2006). The approach assumes default values for carbon stocks in different carbon pools, climate regions and ecosystems and default factors for different management practices. Based on the indications in this guide and the 2006 IPCC Guidelines, we extended the estimates developed by Havlík et al. to carbon pools other than living biomass (soil, dead wood and litter). 


\section{Land use change emissions including dead wood, litter and soil organic carbon}

As demonstrated in Bird et al. (2010) it is important to include dead wood, litter and soil organic carbon (DWLSOC) in the estimates of the emissions from land use change. In the example studies in this paper, not including these three pools underestimates the sequestration in afforestation and reforestation activities by $12 \%$ and underestimates the emissions from deforestation activities by $20 \%$. Underestimating sequestration is 'conservative' since sequestration benefits the environment. However, underestimating emissions from deforestation is significant, and even more so in the case of biofuels since the majority of the predicted land use change due to biofuels is deforestation (Havlík et al. 2011).

\subsection{Methodology}

The IPCC default methodology for emissions from soil organic carbon from land use change assumes a transition between equilibrium soil organic carbon (SOC) in the starting land use and the final land use. This transition occurs over 20 years. Potentially, another transition period occurs for the changes in litter and dead wood carbon stocks associated with a land use change as well. A stand-based model for a single afforestation or deforestation event is easy to calculate, and these models will be discussed in more depth in section 3.3. However, the combination of these models and multiple afforestation or deforestation events requires the use of a convolution model to calculate the emissions from dead wood, litter and soil organic carbon.

Convolution (Wikipedia 2011) is a mathematical operation involving two time-series; in our case, the land use change (LUC) events and a stand-based model representing a single land use change event. The convolution operation involves:

1. Multiplying the stand-based model by the amount of the LUC event; and

2. Moving the starting point of the stand-based model to the time at which the LUC event occurs.
This is done for each LUC event, and the results of each operation are summed. Mathematically,

$$
E_{L U C, t}=L U C_{t}{ }^{*} \operatorname{Stand}_{L U C, t}
$$

Where: $E_{L U C, t}=$ emissions for a specific type of land use change, $L U C_{t}$ is the time series of land use change events, and $\operatorname{Stand}_{L U C, t}$ is the emission time-series for a single land use change event.

Each of the components in this equation will be discussed in more detail below.

\subsubsection{The land use change component}

For the land use change component we have used results on global afforestation and deforestation from the GLOBIOM model (Havlík et al. 2011). GLOBIOM provides estimates of land use competition between the major land-based production sectors and assesses the land use change impacts of biofuel production scenarios in terms of afforestation and deforestation. This study developed the land use change events for four future scenarios of biofuel production using a partial equilibrium economic model. The four biofuel scenarios are:

a. No biofuels are produced;

b. Baseline (60\% of biofuels produced are first generation and $40 \%$ are second generation);

c. Only first generation biofuels are produced; and

d. Only second generation biofuels are produced.

As well, for the second generation biofuels, three options were evaluated. Second generation biofuels are created from short-rotation forestry on agricultural land or on marginal land, or from existing forest lands.

Havlík et al also estimated the $\mathrm{CO}_{2}$ emissions from land use change for the live biomass only. It assumed that agricultural practices do not affect soil carbon emissions and, in the case of deforestation, the total carbon contained in aboveground and belowground living biomass is emitted. 
Compared to other studies of iLUC from biofuels, the GLOBIOM result is on the high side for emissions from land use change Figure 3 summarises the emissions from land use change due to first generation biofuels in various studies. However, these results are not directly comparable to the GLOBIOM estimate. The estimates shown in Figure 3 are for select biofuels for individual regions. The GLOBIOM estimates are for all biofuels due to global demand. Emissions due to land use change from living biomass only in the GLOBIOM first generation scenario are $92 \mathrm{~g} \mathrm{CO}_{2}$-eq/ MJ. In Figure 3, the values for individual biofuel crops range from large sequestration to $150 \mathrm{~g} \mathrm{CO}_{2}$-eq/MJ. For comparison emission intensities of gasoline and diesel are 85.0 and $87.0 \mathrm{~g} \mathrm{CO}_{2}$-eq/MJ respectively.

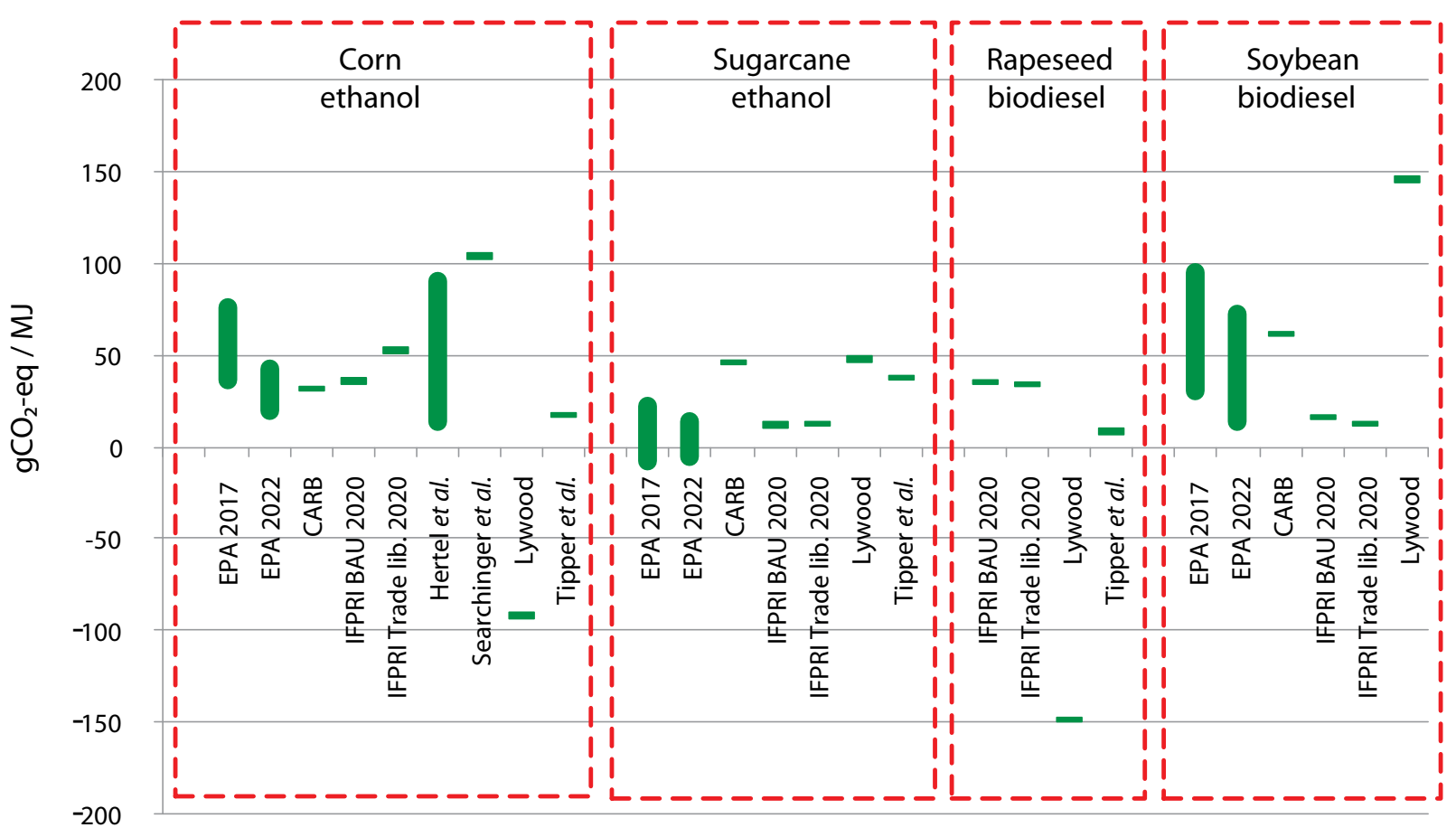

Figure 3. Estimates of emissions from land use change by 2020 due to biofuels from various studies Source: Berndes et al. (2011)

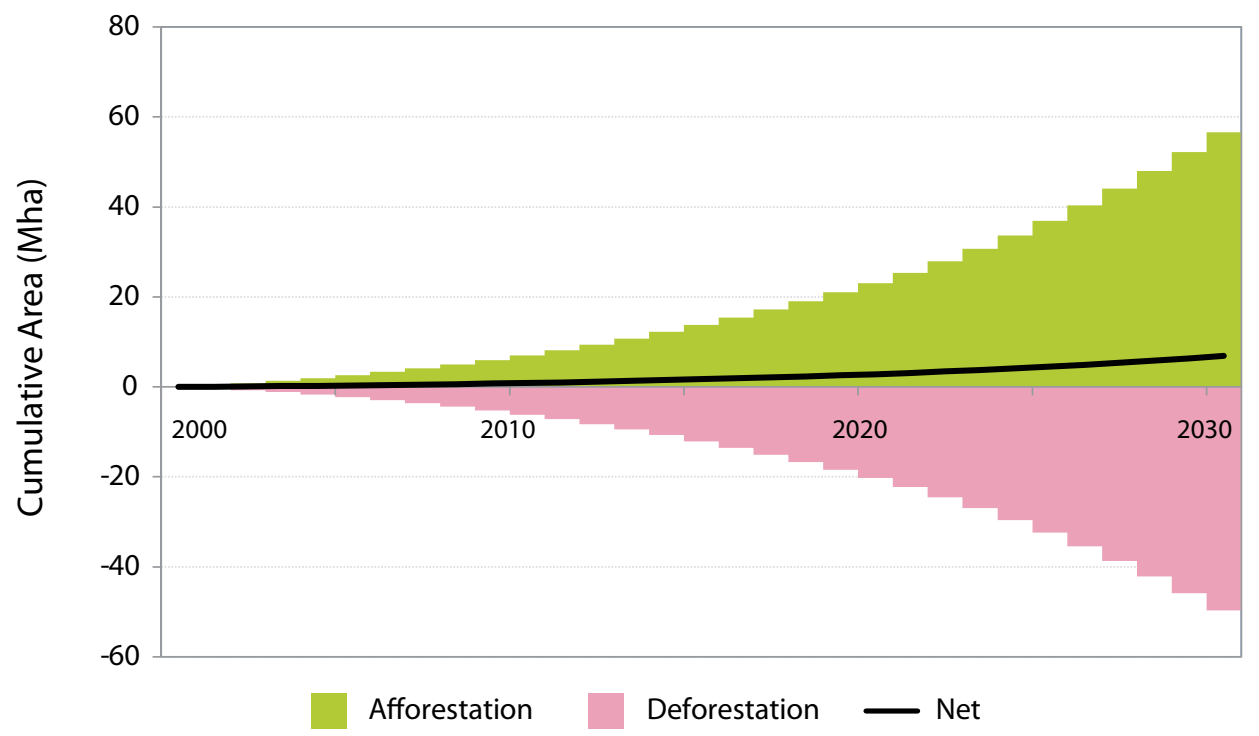

Figure 4. Estimated cumulative afforestation and deforestation and net forest area changes caused by future biofuel production, 2000-2030, baseline scenario, agriland option

Source: Havlík et al. (2011) 
For purposes of this paper, we focus on their results from the baseline scenario with the option that the biomass for second generation biofuels comes from existing agricultural land. The results from Havlík et al. (2011) are shown in Figures 4 and 5. In 2030, the GLOBIOM model (baseline scenario, agriland option) predicts 50 Mha of cumulative deforestation, 19\% occurring in Latin America. For this reason, Latin America is the source of most emissions (Figure 5). Since the task in the work package is to add the emissions due to changes in DWLSOC, we will discuss the sensitivity of our results to the selected scenario from the GLOBIOM model only briefly.

The Havlík et al. study provides estimates of emissions due to changes of carbon stocks in live biomass (aboveground and belowground) at 2000 and 2030. The carbon stock changes are a sum of changes due to afforestation and deforestation. Our study adds:

- The interpolation of the emissions and land use change between 2000 and 2030; and

- The emissions due to changes in dead wood, litter and soil organic carbon.
For the interpolation, we assume that the cumulative emissions and land use changes by year are proportional to the cumulative demand for bioenergy by year as calculated by the International Energy Agency (IEA 2010). The IEA has analysed three scenarios for future energy demand:

- New policies scenario, which assumes that fossilfuel subsidies are completely phased out in all netimporting regions by 2020 (at the latest) and in net-exporting regions where specific policies have already been announced;

- Current policies scenario, which assumes that fossil-fuel subsidies are completely phased out in countries that already have policies in place to do so;

- 450 scenario, which assumes that fossil-fuel subsidies are completely phased out in all netimporting regions by 2020 (at the latest) and in all net-exporting regions by 2035 (at the latest), except the Middle East, where it is assumed that the average subsidisation rate declines to $20 \%$ by 2035 .

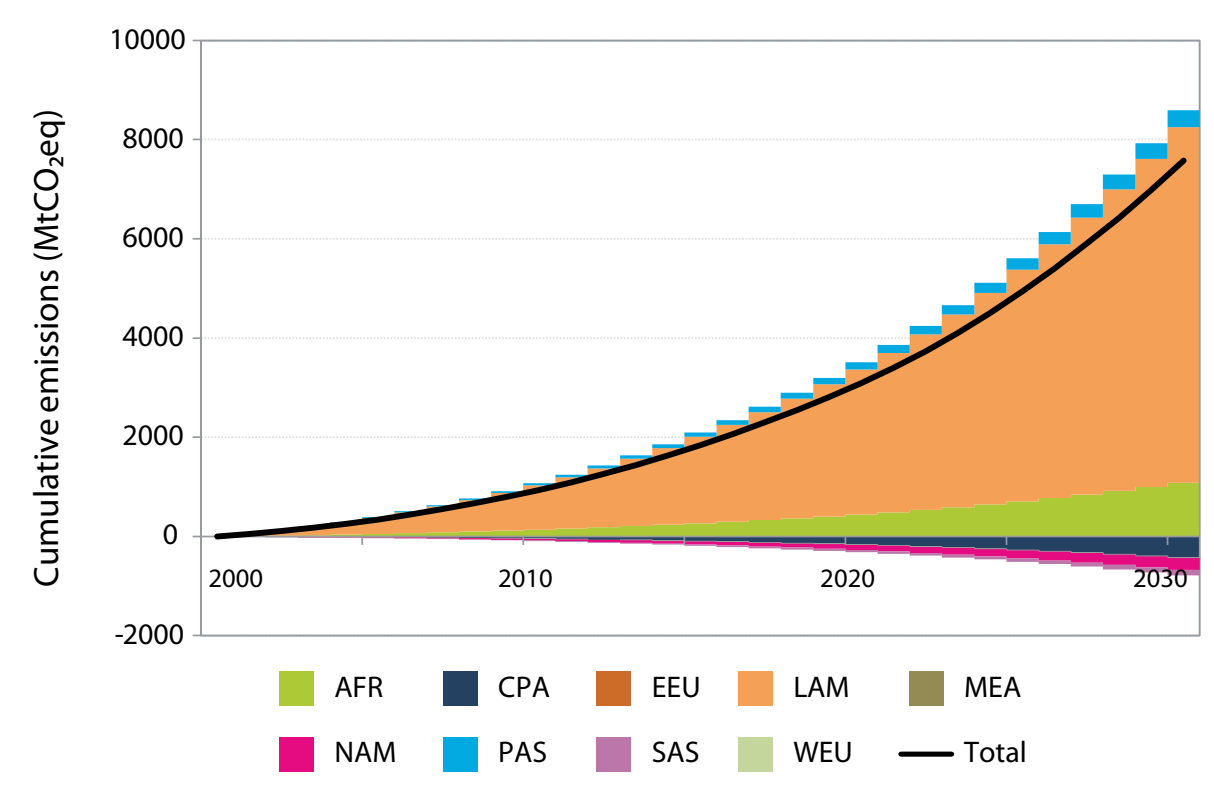

Figure 5. Estimated cumulative net emissions from living biomass due to land use change caused by biofuels, 2000-2030, baseline scenario, agriland option

Source: Havlík et al. (2011)

Abbreviations: AFR = sub-Saharan Africa, CPA = centrally planned Asia, EEU = Central and Eastern Europe, LAM $=$ Latin America, MEA = Middle East and North Africa, NAM = North America, PAS = Other Pacific Asia, SAS = South Asia, WEU = Western Europe. 
For our interpolation, we have used demand projections for the 450 scenario because it most closely matches the production estimate for 2000 and 2030 in the GLOBIOM model.

\subsubsection{Stand models}

Estimates of the carbon emissions for removals in litter, dead wood and soil due to afforestation or deforestation have been added to the original GLOBIOM results. These emissions/removals are calculated as the difference of carbon stock in each of the three pools, before $[C(0)]$ and after $[C(1)]$ conversion. The carbon stock change is converted to $\mathrm{CO}_{2}$ emissions/removals:

$$
\triangle C O_{2 i}=\left[C(1)_{i}-C(0)_{i}\right] \times 44 / 12
$$

$i$ : carbon pool (dead wood, litter or soil organic carbon).

The annual emissions/removals are calculated over a conversion period, which is the time needed to reach a new equilibrium once the land use is changed.

The assessment has been made based on default values provided in the 2006 IPCC Guidelines. Default values are provided for carbon stocks in each pool and for each land use. Afforestation on cropland, grassland or other natural vegetation and deforestation are the land use changes included in the analysis. Afforestation considers only conversion to short-rotation plantations, while deforestation is the conversion of natural or managed forests to other land uses, such as cropland and grassland. The calculations are done at the regional level for 11 regions (Central and Eastern Europe, the former Soviet Union, Latin America, Middle East and North Africa, North America, other Pacific Asia, Pacific OECD, Planned Asia-China, South Asia, subSaharan Africa, Western Europe).

For each region and carbon pool, we chose a carbon stock value among the default values reported for the ecosystems and the climatic zones included in that region. To identify the default values for each region, we overlapped the map of the regions from the GLOBIOM model with the map of the IPCC ecological zones (Figure 6) (IPCC 2006). We made the assessment twice, once for the highest and once for the lowest default values for each of the three DWLSOC carbon pools and for each region. For example, the region 'sub-Saharan Africa' includes the climate zones tropical dry and wet and subtropical dry and wet. Table 2.2 of the IPCC Guidelines reports default values for carbon stock in forest litter, and a distinction is made between broadleaf and coniferous forests. The highest carbon stock for the climate zones in the sub-Saharan Africa region is for the tropical needle-leaf evergreen forest, while the lowest is for the tropical broadleaf deciduous forest.

It is assumed that changes in the litter and dead wood pool occur only with deforestation, while no change is assumed in the other cases. Carbon loss equal to the amount of carbon in the litter and dead wood is accounted for when a forest is cut and converted to cropland or grassland. This assumption is based on an IPCC Tier 1 approach, which considers no accumulation of litter and dead wood in cropland and grassland. Therefore, deforestation produces a loss of carbon in these two pools. Initial values of litter and dead wood carbon in forests were derived from Table 2.2 of the 2006 IPCC Guidelines (IPCC 2006) and Table 3.2.2 of the 2003 IPCC Guidelines (IPCC 2003). Regarding afforestation, the data only include conversions to short-rotation plantations, which accumulate very little litter and dead wood compared to cropland or grassland.

For this reason, we conservatively assumed that no carbon is accumulated in litter and dead wood when land is converted to short-rotation plantations.

The emissions/removals in soil are calculated based on Equation 2.25 and default factors in the 2006 IPCC Guidelines. According to this method, the carbon stock in the soil under a specific land use is calculated by first selecting a so-called reference soil carbon stock (SOC REF , Table 2.3, IPCC 2006). The $S_{\mathrm{SOC}}$ REF represents the carbon stock in reference conditions, i.e. native vegetation that is not degraded or improved. The $\mathrm{SOC}_{\mathrm{REF}}$ is the value that we used as soil carbon stock in forestland. For other land uses, the soil carbon stock is calculated by multiplying the $\mathrm{SOC}_{\mathrm{REF}}$ for default factors that are specific for each land use, land management and level of organic inputs (Tables 5.5, 5.10 and 6.2, IPCC 2006).

Default $\mathrm{SOC}_{\mathrm{REF}}$ values were chosen among the figures reported for high-activity clay soils that include most of the existing soil types.

Figure 7 shows the stand-based model emission time series from DWLSOC due to deforestation in Latin America. 
A

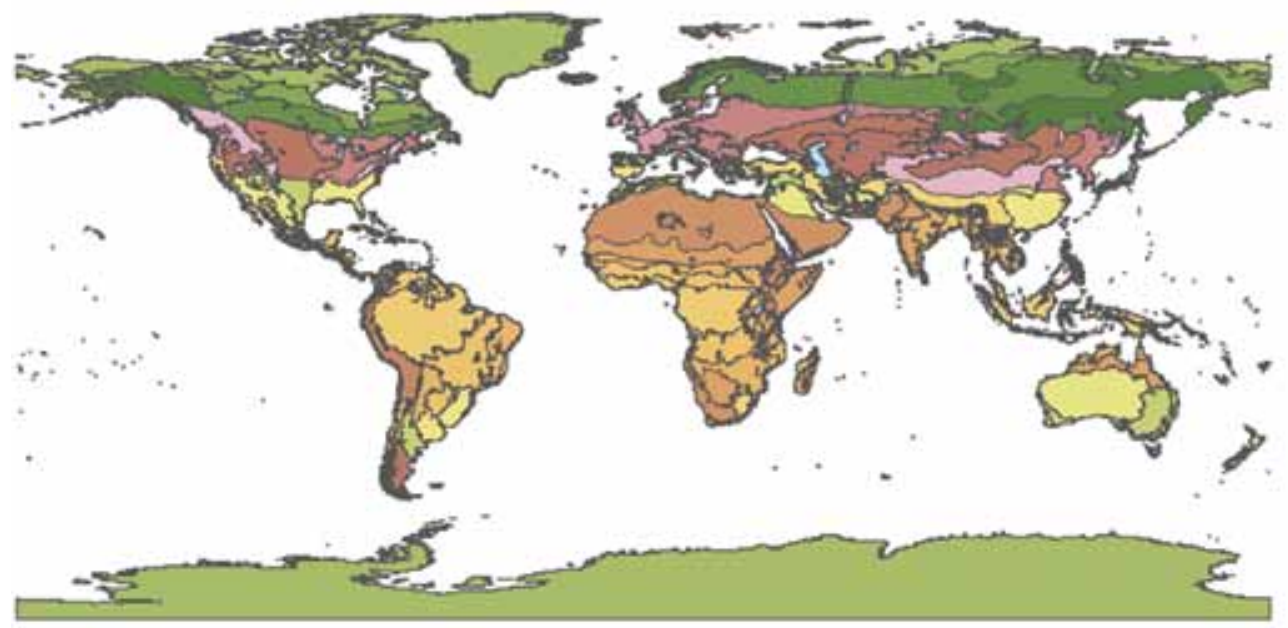

\section{Ecological zones}

BM, Boreal mountain system

TAwb, Tropical dry forest

$\square$ Ba,Boreal coniferous forest

$\mathrm{Bb}$, Boreal tundra woodland

TBSh, Tropical shrubland

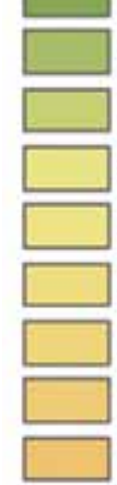

P. Polar

SBSh, Subtropical steppe

SBWh, Subtropical desert

SCf, Subtropical humid forest

$\mathrm{SC} \&$, Subtropical dry forest

SM, Subtropical mountain system

TAr, Tropical rainforest

TAwa, Tropical moist deciduous forest

\section{TBWh, Tropical desert}

TM, Tropical mountain system

TeBSk, Temperate steppe

TeBWk, Temperate desert

$\square$ TeDc, Temperate continental forest

$\square$ TeDo, Temperate oceanic forest

$\square$ TeM, Temperate mountain system

$\square$ Water, Water

$\square$ n.d., No data

B

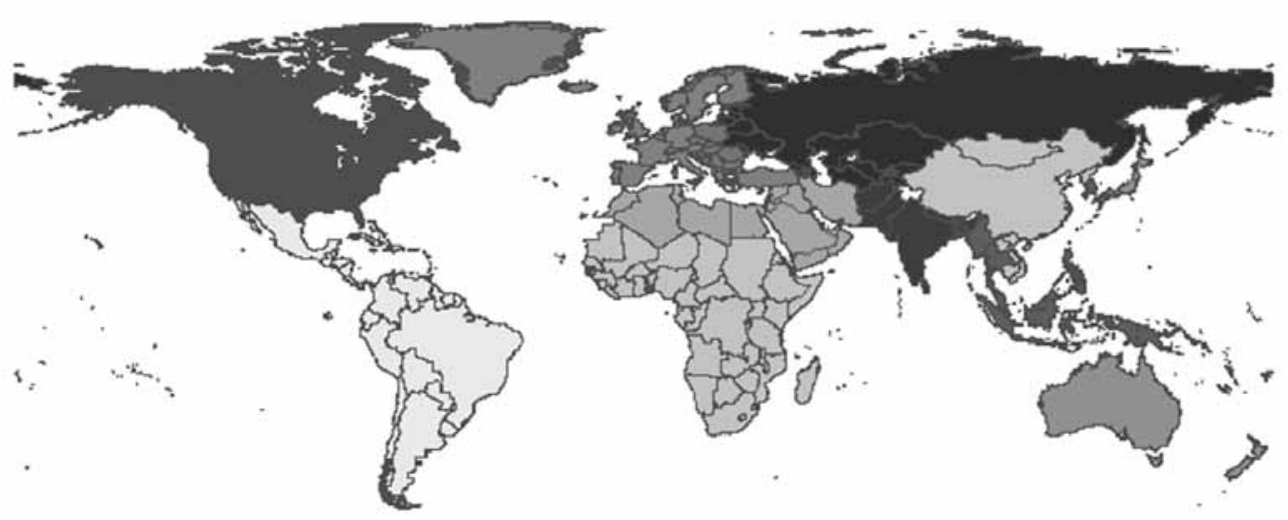

\section{Regions}

$\square$ CentralEastEurope
FormerSovietUnion
$\square$ LatinAmericaCarib
$\square$ MidEastNorthAfrica

NorthAmerica
OtherPacificAsia
$\square$ PacificOECD
$\square$ PlannedAsiaChina

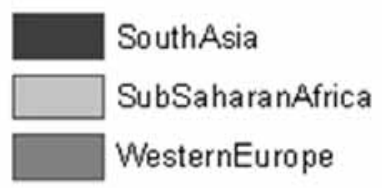

Figure 6. Map of the ecological zones from IPCC 2006 (A) and map of the regions of the GLOBIOM model (B) 


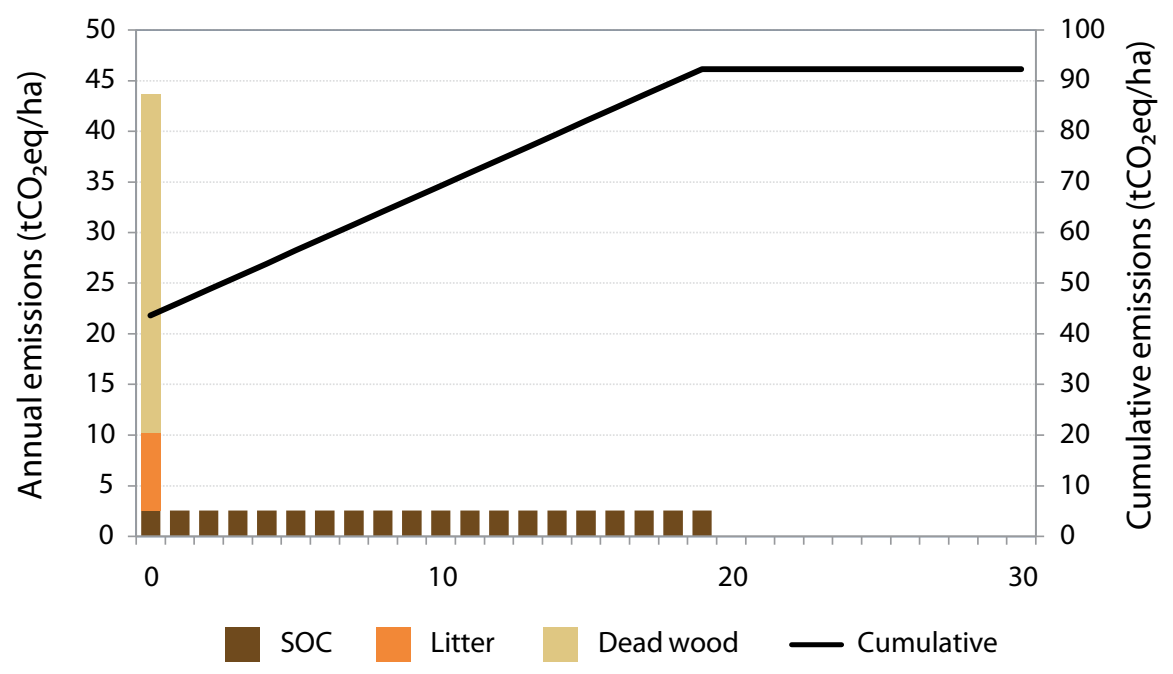

Figure 7. Stand-based model emissions from DWLSOC: example of deforestation in Latin America

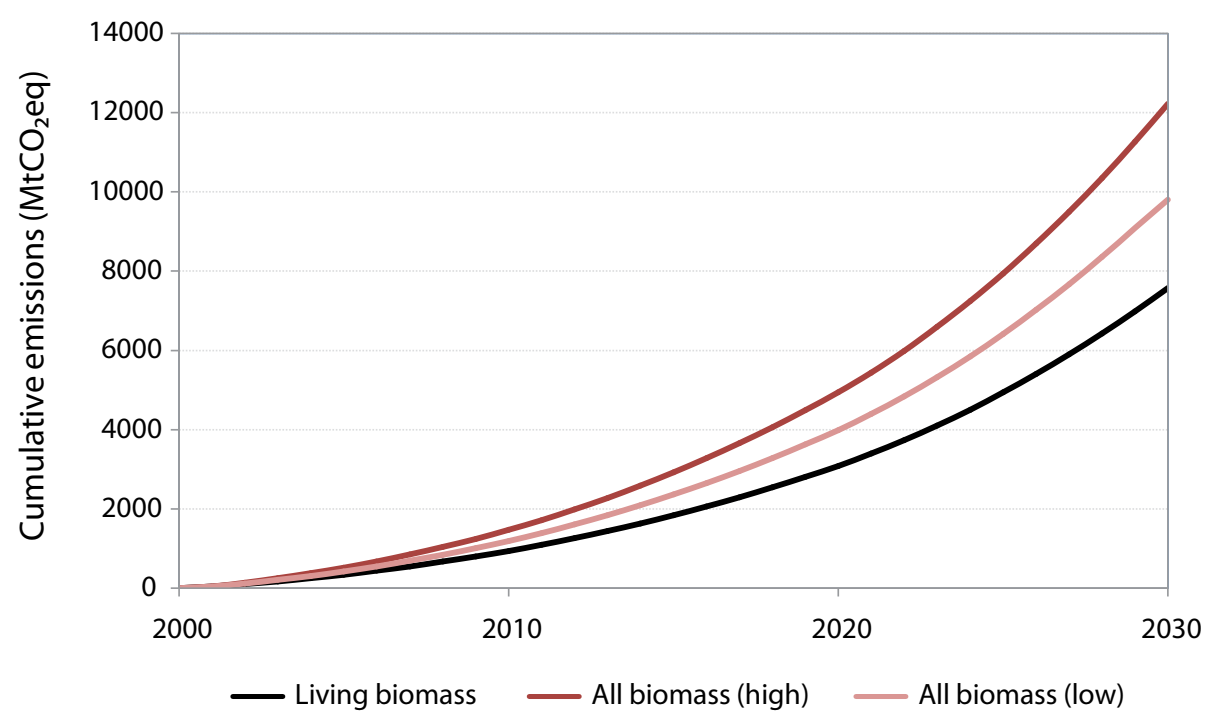

Figure 8. Estimated cumulative emissions from all biomass due to land use change caused by biofuels, 2000-2030, baseline scenario, agriland option

\subsection{Results}

The results of adding the emissions due to changes in DWLSOC are shown in Figure 8. The cumulative emissions due to DWLSOC from 2000 to 2030 add between $30 \%$ and $61 \%$ to the cumulative emissions from living biomass. DWLSOC emissions are between $23 \%$ and $38 \%$ of the total cumulative emissions from land use change due to biofuel production, that is, of the total emissions from all carbon pools. This value is very comparable to the example of deforestation from Mexico in Bird et al. (2010). In Bird et al. (2010), using a detailed carbon model, it was estimated that emissions from DWLSOC comprised $20 \%$ of the total emissions due to deforestation.

A recent report released by the Joint Research Centre also provides an estimate of GHG emissions from land use change caused by biofuel production (Hiederer et al. 2010). The study includes estimates of emissions from dead wood, litter and soil, but dead wood and litter are included in the figures for aboveground and belowground biomass carbon 
A

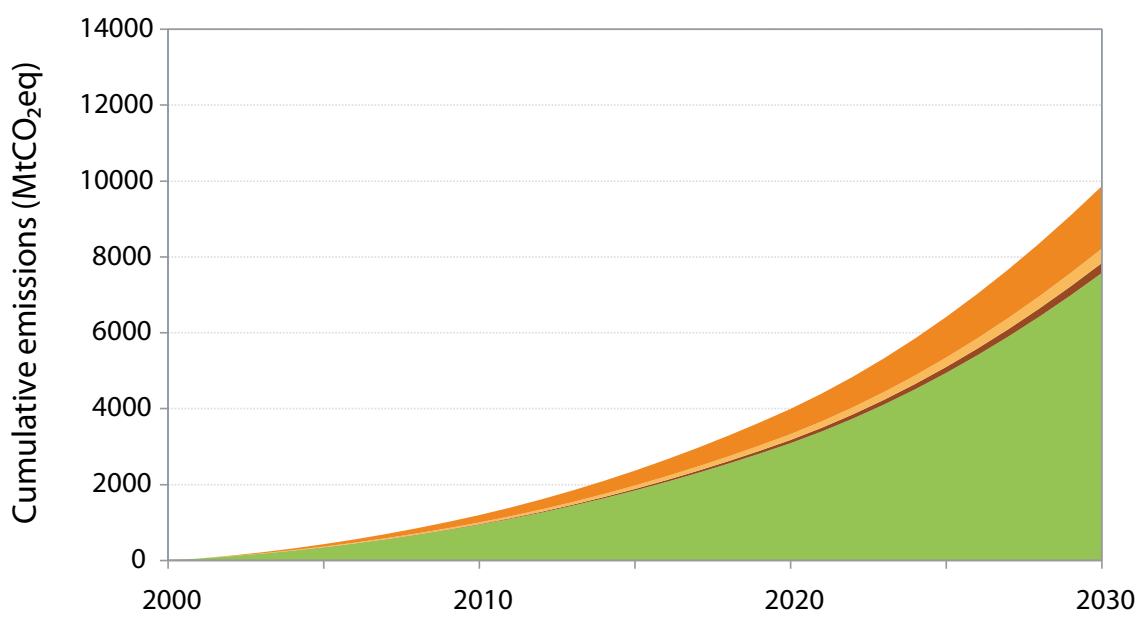

B

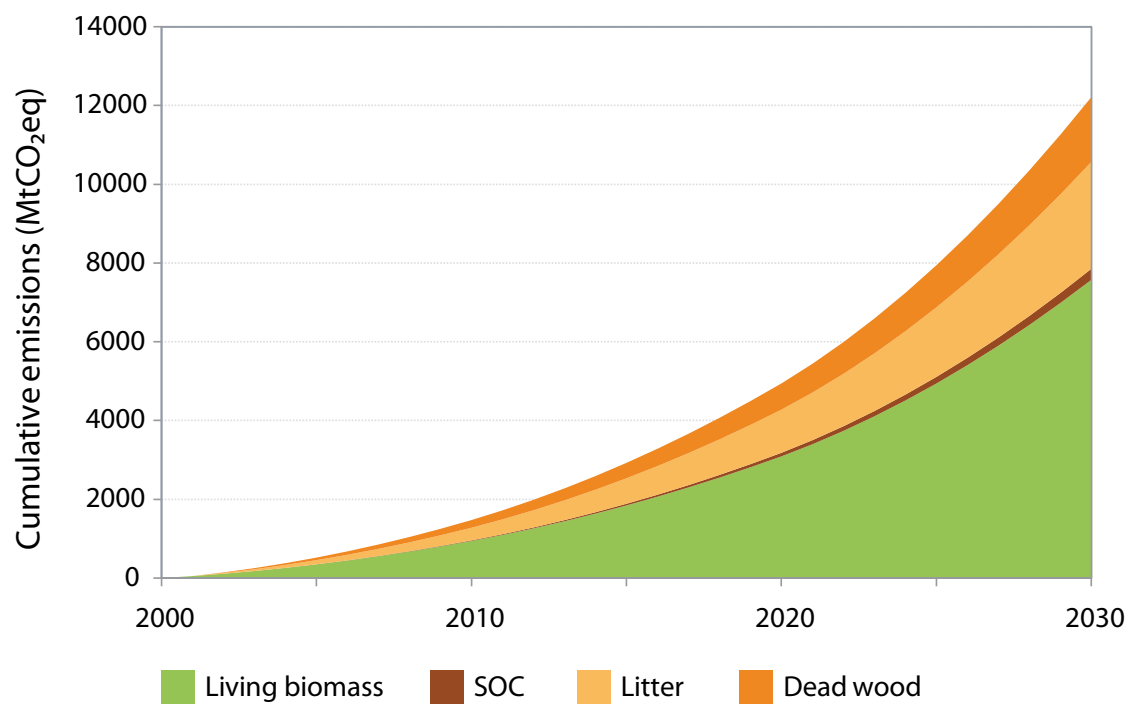

Figure 9. Contribution of different carbon pools to overall emissions from land use change when low (A) or high (B) default values for dead wood, litter and soil are selected, baseline scenario, agriland option

stock' (ABCS). The results show that changes in soil organic carbon stock contribute about $15-20 \%$ of the total $\mathrm{CO}_{2}$ emissions. It is reported that dead organic matter (dead wood and litter) represents about $5 \%$ of the ABCS on average in closed forests globally. Therefore, we can roughly determine that $20-25 \%$ of the total $\mathrm{CO}_{2}$ emissions from land use change are attributable to carbon stock changes in DWLSOC. In Hiederer et al.(2010), no effort is made to calculate annualised emissions from different carbon pools. All carbon stock changes are assessed as the difference of carbon stock before and after the conversion, and they are annualised over a period of 20 years.

\subsection{Sensitivity to DWLSOC assumptions}

The chosen default values and factors have a significant impact on the estimates of the land use change emissions/removals. As shown in Figure 8, when high default values of carbon stock in dead wood, litter and soil are selected, the emissions from DWLSOC are almost double compared with low default values.

The results are also very sensitive to the type and number of carbon pools included in the analysis (Figure 9). 
According to our estimates, the inclusion of the dead wood pool has a strong impact on the final results, with either high or low default values. However, when high default values are selected, the litter pool becomes the most significant source of emissions after living biomass. Soil organic carbon, instead, seems to be a marginal source of emissions. This might be due to the fact that soil carbon losses after deforestation are partially compensated by soil carbon gains in afforested areas, while we assumed that no litter or dead wood is accumulated by afforestation (i.e. short-rotation plantations). In addition, we assumed that carbon in litter and dead wood is emitted in the first year after deforestation, while soil organic carbon losses are distributed over a longer period (20 years). These assumptions might influence the contribution of different carbon pools on the overall land use emissions.
A change of the period on which soil carbon emissions are annualised has a negligible impact on the final results. For instance, if we assume that a new equilibrium of soil carbon stock is reached 50 years after deforestation, instead of 20 years after, no change of overall emissions from land use change is detected. However, when carbon stock changes in dead wood and litter are annualised over a period of 20 years, the total emissions from land use change decrease by $10-20 \%$ in 2030 . In this case, the contribution of emissions from DWLSOC on the total land use emissions is $14 \%$ (low default values) to $24 \%$ (high default values), rather than $23 \%$ to $38 \%$. 


\section{Emissions from biofuels compared to emissions from fossil fuels}

With the addition of DWLSOC arises the question, 'will greenhouse gas emissions be reduced if globally we use biofuels in the amount predicted in place of fossil fuels?' We have answered this question by including the estimates of the GHG emissions from the cultivation, processing, transport and distribution of biofuels, the non-LUC components to the emissions due to LUC. For example, if corn is transformed into ethanol, the non-LUC components are the emissions for using machinery to plough the land, transport the biomass to the ethanol plant, convert the biomass to ethanol and distribute the ethanol to the consumer. There are also emissions from the use of inorganic nitrogen-based fertilisers that must be included. These emissions are usually included in a life cycle assessment (LCA) of the impacts of biofuels. It is important to note that emissions from the combustion of biofuels are not included in the calculation since, following the current IPCC accounting convention, they are included as emissions from land use change.

We have also calculated the emissions due to extraction, processing, transport, distribution and combustion of fossil fuels that the biofuels replace. For this calculation we have used published emission factors per unit energy of biofuel and fossil fuel consumed, listed in Appendix 2.
The comparison excluding DWLSOC is shown in Figure 10. We find that both biofuels and fossil fuels cause significant GHG emissions. The cumulative emissions from non-LUC are approximately $44 \%$ of the cumulative emissions due to changes of living biomass. In addition, the cumulative emissions from fossil fuels are greater than those from biofuels in 2024. Havlík et al. (2011) reported that between 10 and 27 years are required before recovery (by saving fossil fuel emissions) of the land use change emissions from individual biofuel actions. This is often referred to as carbon payback time. Other authors (Gibbs et al. 2008; Fargione et al. 2008; Searchinger et al. 2008) have reported payback times of individual land use changes of 10 to 400 years. Havlík et al. (2011) include the LCA emissions in their analysis, but the other authors do not. They also consider only the payback time of individual land use changes and not the impacts of the global biofuel demand. Both of these factors are included in our study.

When DWLSOC are included (Figure 11) one sees that the cumulative total emissions from biofuels, including LUC and non-LUC, are always greater than the fossil fuels they replace. This may appear to contradict the previously cited studies. However, it is important to recognise that even though an individual land use change has a payback time, the

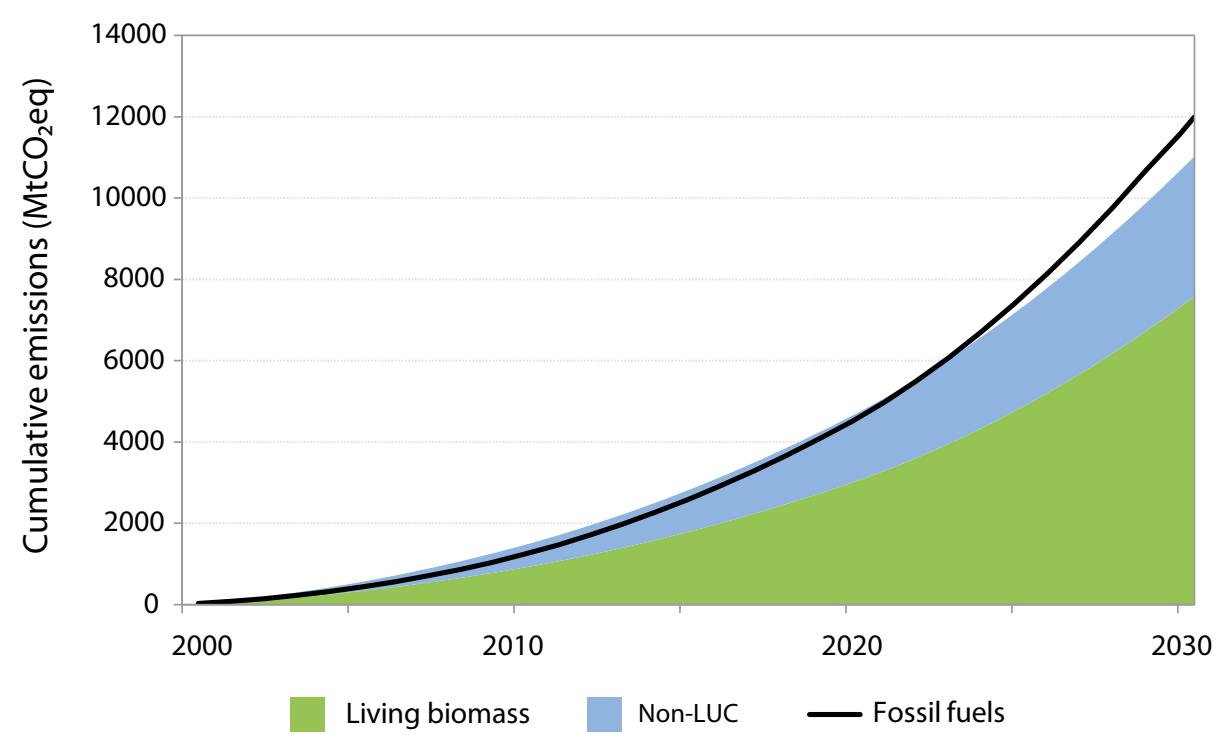

Figure 10. Cumulative emissions from fossil fuels and biofuels without DWLSOC, baseline scenario, agriland option 


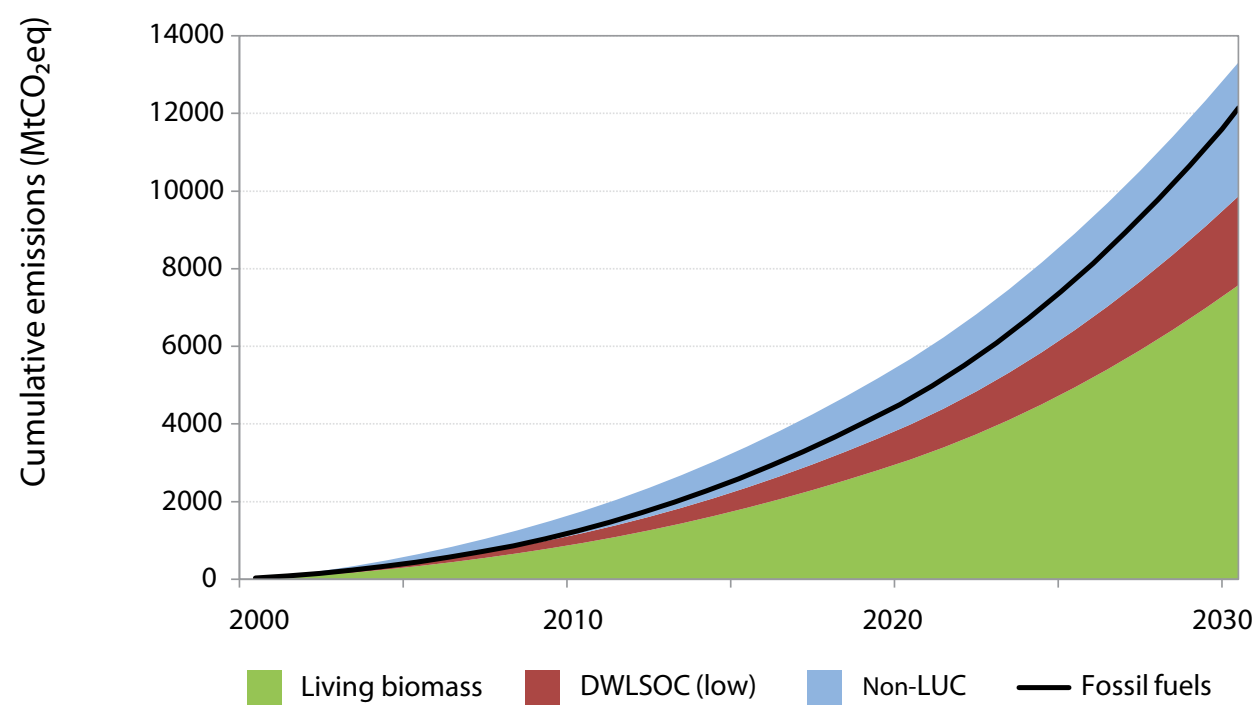

Figure 11. Cumulative emissions from fossil fuels and biofuels with DWLSOC, baseline scenario, agriland option

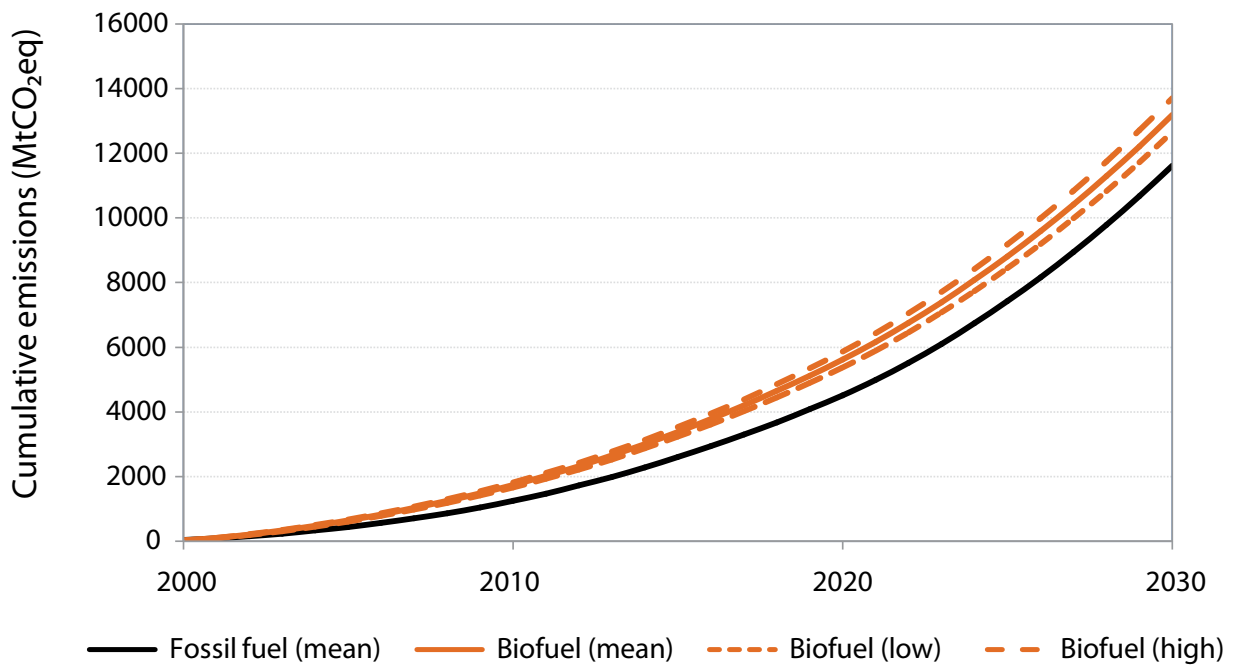

Figure 12. Sensitivity of cumulative emissions from fossil fuels and biofuels (with DWLSOC) to variability in LCA emission factors, baseline scenario, agriland option

time series for the policy may not ever reach payback if the bioenergy consumption is always increasing. This is analogous to deficit spending by credit-card holders whose incomes are increasing but who continue to put purchases on the credit card without paying off the balance. They fall farther and farther behind until the increase in their spending falls behind their growth in income.

\subsection{Sensitivity to Life Cycle Assessment assumptions}

The life cycle assessment (LCA) emission factors are not accurate (see Appendix 2) However, the major component of the cumulative emission estimate comes from the land use change estimate and not the emission factors used in the LCA. As a result, a Monte Carlo simulation of model results, assuming that a parameter is normally distributed and with a standard deviation of range/2, shows relatively little variance in estimates (Figure 12).

The major variation in cumulative emissions is caused by the assumed scenarios. The different scenarios come from the Havlík study and are not part of this paper. However, for completeness, a brief discussion of the sensitivity to scenarios is given in Appendix 1. 


\section{Accounting using alternative systems}

Pena et al. (2011) described and evaluated a range of alternative accounting systems for bioenergy. The text that follows is a recapitulation of this activity and is provided for readers not familiar with that publication.

There are three basic philosophies underlying the accounting of GHG emissions from bioenergy:

- Combustion factor $=\mathbf{0}: \mathrm{CO}_{2}$ emissions produced when biomass is burned for energy are not counted at the point of combustion; the emissions are accounted for in the land use sector as carbon stock losses;

- Combustion factor $=\mathbf{1}: \mathrm{CO}_{2}$ emissions produced when biomass is burned for energy are counted at the point of combustion; emissions are accounted for in the energy sector; uptake of $\mathrm{CO}_{2}$ from the atmosphere by plants and soils may, or may not, be accounted for.

- Value-chain approaches: End users are responsible for all or a specified subset of emissions that occur along the bioenergy value chain regardless of where these emissions occur. Value chain approaches can use (1) calculated emissions to determine whether bioenergy is eligible to meet a regulatory requirement or (2) the calculated emissions to derive a combustion factor potentially other than ' 0 ' or ' 1 ' to be used in conjunction with combustion emissions.

The concept underlying the 'combustion factor $=0$ ' approach is that as long as sufficient biomass grows to replace combusted biomass (bio- $\mathrm{CO}_{2}$ equals or exceeds bioenergy $\mathrm{CO}_{2}$ ), there are no atmospheric consequences: the atmospheric $\mathrm{CO}_{2}$ burden will not rise. The atmospheric burden only increases if harvesting exceeds growth, in which case a reduction in carbon stocks occurs, and the system assumes this reduction will be registered in the accounting system. As long as carbon stock reductions do not occur, or do not appear in the accounting, no emissions are attributed to use of biomass for energy. The system used for reporting under the UNFCCC, and subsequently adopted for accounting under the Kyoto Protocol, in essence multiplies the $\mathrm{CO}_{2}$ emissions that occur when biomass is combusted for energy by zero and relies on counting changes in carbon stock levels in the land use sector to measure the atmospheric impact of biomass use.

The basic alternative to using a 0 -combustion factor is to treat emissions from biomass in the same way as emissions from fossil fuels. Emissions from use of fossil fuels are accounted for at the point of combustion (i.e. a combustion factor of 1 is applied to $\mathrm{CO}_{2}$ emissions). Pena et al. (2011) discussed two accounting options under this general approach: tailpipe and point of uptake and release (POUR).

Tailpipe: We use the term 'tailpipe' for a system in which only the flows to the atmosphere are considered; changes in carbon stocks are not included in the accounting. Under this accounting system, emissions from bioenergy are treated in the same way as emissions from fossil fuels, where the change in stocks plays no role. The biomass consumer uses an emission factor of ' 1 ' for $\mathrm{CO}_{2}$ emissions when the biomass is combusted. No measurements of carbon stock changes need to be undertaken to determine the impact of biomass use for energy. Only the flows to the atmosphere from bioenergy combustion appear. If carbon stock reductions were to be accounted for, the system would need to include a mechanism to avoid double counting of the emissions due to use of biomass for energy.

Point of uptake and release (POUR): Under POUR, net $\mathrm{CO}_{2}$ uptake or emissions by plants from the atmosphere is accounted for. This is the sum of carbon stock changes in the landscape plus carbon removed from the landscape for all purposes (i.e. carbon removed by plants from the atmosphere that is embodied in products). Since total $\mathrm{CO}_{2}$ removed is accounted for under POUR, it is appropriate to account for all returns of carbon to the atmosphere- both from combustion and decay of biomass products - when and where they occur. Both tailpipe and POUR account for the emissions due to combustion of bioenergy, but POUR also accounts for the net emission removals 
from plants. POUR also differs from 0-combustion systems in its approach to accounting for land-sector emissions and removals.

Under POUR the biomass producer accounts for all carbon taken up through growth and the consumer accounts for emissions from combustion of biomass. Contrary to common belief, one does not need to measure fluxes to and from the atmosphere in this accounting system. The total $\mathrm{CO}_{2}$ uptake at the biomass production point can be estimated by adding carbon stock change between year $t_{0}$ and $t_{1}$ to the total amount of biomass embodied in products of all types, i.e. consumers of biomass for food and long- and short-lived wood products as well as for energy. Including the biomass embodied in products minimises the chance of double-counting emissions for bioenergy consumption and stock changes.

In value chain systems, $\mathrm{CO}_{2}$ emissions and removals that occur throughout the entire production, conversion, transportation and consumption processes are considered the responsibility of the consumer. A value chain approach is similar to a LCA except it considers more than just GHG emissions. It includes, for example, details of production or conversion processes, energy balances, inflows and outflows of materials, and environmental impacts of waste disposal. Value chain approaches in the climate context only consider GHG emissions and removals; they do not need to consider either conversion process details or material inflows and outflows.

Value chain approaches may estimate or measure net increases or decreases in carbon stocks due to land use or management changes; emissions due to cultivation, including emissions due to use of fertilizers, liming and tillage; emissions due to harvesting operations and transportation to a conversion facility; emissions due to conversion processes, including from fossil fuels and fermentation; transportation to distributors or end users of fuels; and emissions due to combustion. The EU Renewable Energy Directive (European Union 2009) and the US Renewable Fuel Standard are examples of a value-chain approach.

Table 1 lists the cumulative emissions from biofuels in 2030 by region estimated under different accounting systems. The emissions from the tailpipe accounting system and the displaced fossil fuels are provided for comparison. The tailpipe approach has unrealistically large total emissions, even larger than the emissions from fossil fuels displaced by

Table 1. Total cumulative emissions caused by biofuels in 2030 by region under different accounting systems

\begin{tabular}{|c|c|c|c|c|c|}
\hline \multirow{2}{*}{ Region } & IPCC & POUR & Value chain & Tailpipe & Displaced fossil fuels \\
\hline & \multicolumn{5}{|c|}{ All units in Mt CO2eq } \\
\hline AFR & 95 & 106 & 15 & 106 & 14 \\
\hline CPA & -34 & 35 & 92 & 35 & 89 \\
\hline EEU & 0 & 11 & 15 & 11 & 14 \\
\hline FSU & 0 & 0 & 0 & 0 & 0 \\
\hline LAM & 880 & 316 & 162 & 1001 & 157 \\
\hline MEA & 0 & 22 & 29 & 22 & 28 \\
\hline NAM & -12 & 254 & 386 & 277 & 374 \\
\hline PAO & 0 & 19 & 26 & 19 & 25 \\
\hline PAS & 66 & 66 & 0 & 66 & 0 \\
\hline SAS & -10 & 61 & 96 & 61 & 93 \\
\hline WEU & -15 & 80 & 151 & 97 & 146 \\
\hline Total & 970 & 970 & 970 & 1696 & 940 \\
\hline
\end{tabular}

Abbreviations: AFR = sub-Saharan Africa, CPA = centrally planned Asia, EEU = Central and Eastern Europe, FSU = Former Soviet Union, LAM = Latin America, MEA = Middle East and North Africa, NAM = North America, PAO = Pacific OECD, PAS $=$ Other Pacific Asia, SAS = South Asia, WEU = Western Europe. 
the biofuels, since it does not include any emissions or removals (sequestration) from LUC caused by biofuels.

In IPCC, POUR and value-chain accounting, the amount of emissions from biofuels allotted to the consumer of the biofuels varies from left to right in the table. In the IPCC accounting approach, the consumer has the least emissions, because the emissions from LUC and LCA emissions from production of the biofuels are the responsibility of the producer. In the POUR system, the emission burden caused by biofuels shifts. The consumer is responsible for the emissions due to combustion of the biofuels, and the producer is responsible for the LCA emissions for production. The producer is also responsible for the emissions from land use change, but the producer is allotted the sequestration of the carbon in the biofuels. Finally, in a valuechain approach all emissions are the responbility of the consumer.

With this conceptual basis in mind, it is possible to explain the differences between IPCC, POUR and value-chain accounting that occur for various regions.
Latin America sees a large decrease in emissions from IPCC to POUR since, in the Havlík study, Latin America it is a large producer of biofuels. Hence, the large emissions from land use change in the IPCC accounting approach are reduced by the carbon embodied in the produced biofuels in the POUR approach. When switching to a value-chain accounting system, the land use change emissions become the burden of the large consumer of biofuels (North America and Western Europe).

Centrally planned Asia, North America, Pacific OECD, South Asia and Western Europe, as predominantly consumers of biofuels, see an increase in emissions when switching from an IPCC to a POUR to a value-chain accounting approach.

Two regions show more complicated changes when switching accounting systems. Sub-Saharan Africa in the GLOBIOM model is a limited consumer (not a producer) of biofuels. However, some emissions from land use change occur as a result of biofuels. This land use change is not to produce biofuels directly. It is land use change to increase food production caused by a loss of food production in another region as a result of the introduction of biofuels. As a result, a

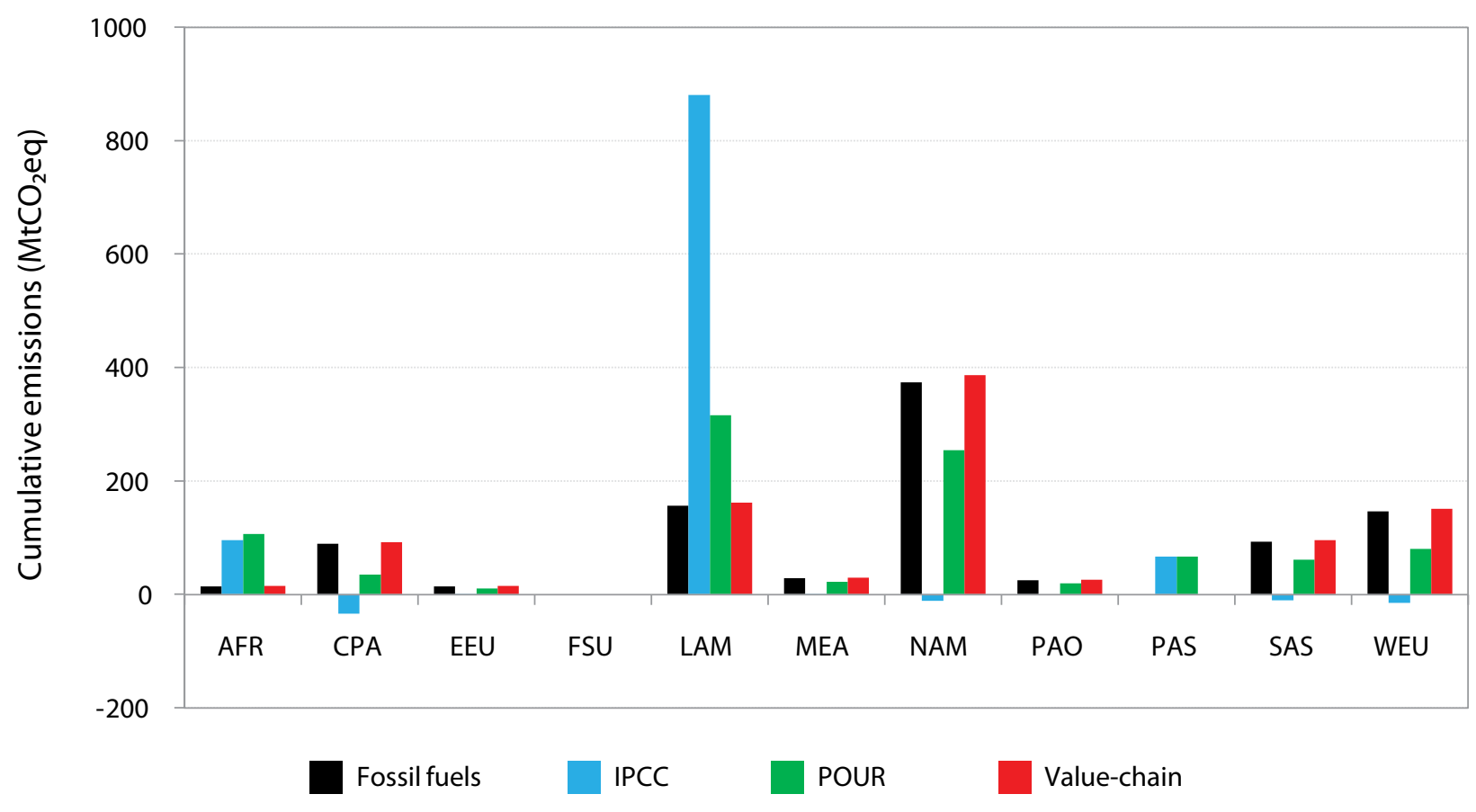

Figure 13. Emissions by region under different accounting systems. baseline scenario, agriland option

Abbreviations: AFR = sub-Saharan Africa, $C P A=$ centrally planned Asia, EEU = Central and Eastern Europe, FSU = Former Soviet Union, LAM = Latin America, MEA = Middle East and North Africa, NAM = North America, PAO = Pacific OECD, PAS = other Pacific Asia, SAS = South Asia, WEU = Western Europe. 
switch from IPCC to POUR results in an increase of emissions due to the emissions from the combustion of biofuels. Under a value-chain accounting approach, the emissions decrease since this region does not consume much biofuel. Other Pacific Asia shows a similar change under the different accounting approaches. However, this region does not consume any biofuels in the GLOBIOM model.

Figure 13 shows graphically the emissions from fossil fuels and biofuels by region under different accounting systems. It shows that under the IPCC accounting system, consuming regions (centrally planned Asia, North America, sub-Saharan Africa and Western Europe) benefit greatly and will claim an emission reduction. On the other hand Latin America, the main producer, is burdened with a large amount of emissions under the IPCC approach. Using POUR accouting, Latin America still has large emissions, but it does not underwrite the emission reductions by the consuming regions. The consumer regions still see a reduction of emissions when compared to fossil fuels.

Each of the accounting systems has benefits and drawbacks. We believe that POUR most realistically allocates the emissions and removals to the regions where they actually occur. In addition, only emissions and removals that are under control of a region are allocated to the region. However, POUR may result in a disincentive for bioenergy. For a more in-depth assessment of the benefits and drawbacks of each accounting system, including possible influences on incentives, please see Pena et al. 2011.

\subsection{Partial participation}

As pointed out by Searchinger et al. (2008) and Pingoud et al. (2010), the IPCC system does not work well under the Kyoto Protocol because it does not account for many land-sector emissions. Landsector emissions fail to get counted in:

1. Non-Annex I countries because they do not have accounting obligations;

2. Annex-I countries that have not ratified the Kyoto Protocol (e.g., the United States); and

3. Annex-I countries that have ratified the Kyoto Protocol where emissions occur:

a. Due to management changes in nations not electing to report emissions from management of, for example, forest, grassland and agricultural lands; ${ }^{1}$ and

b. Due to deforestation that occurs in nations experiencing stable or net gains in land area. Emissions due to deforestation tend not to be reported in this situation because most forest inventories only report net changes in forest area; reforestation and deforestation are not reported separately.

In this section, we analyse the emissions assuming partial participation by regions. Two options are analysed:

- Only current Annex I countries participate; and

- Annex I countries participate and non-Annex I countries are responsible for emissions from land use change.

\section{Only Annex I countries participate}

Table 2 displays the cumulative emissions caused by biofuels in 2030 assuming only Annex I countries participate in the accounting system. It shows that the IPCC accounting approach would register a sequestration of $27 \mathrm{Mt} \mathrm{CO}_{2}$ eq, even though in actuality the cumulative emissions from biofuels are $970 \mathrm{Mt} \mathrm{CO}_{2}$ eq. In addition, Annex I countries would claim that biofuels reduced their emissions by $559 \mathrm{Mt} \mathrm{CO}_{2}$ eq.

The POUR and value-chain accounting systems perform better than the IPCC approach if one assumes partial participation. These two systems would account for 364 and $577 \mathrm{Mt} \mathrm{CO}_{2}$ eq respectively. Clearly they are better than an IPCC approach, but still short of the actual cumulative emissions caused by biofuels (POUR would capture $38 \%$ and value chain $59 \%$ of actual emissions).

\section{Annex I countries participate and non-Annex I countries are responsible for emissions from land use change.}

With the ongoing international negotiations on reducing emissions from deforestation and forest degradation (REDD), it is instructive to analyse the effectiveness of various GHG accounting systems

1 The Kyoto Protocol only requires reporting of emissions and removals due to afforestation, reforestation and deforestation. 
Table 2. Cumulative emissions from land use change caused by biofuel production

\begin{tabular}{|c|c|c|c|c|c|}
\hline \multirow{2}{*}{ Region } & IPCC & POUR & Value chain & Tailpipe & Displaced fossil fuels \\
\hline & \multicolumn{5}{|c|}{ All units in $\mathrm{Mt} \mathrm{CO}_{2} \mathrm{eq}$} \\
\hline \multicolumn{6}{|l|}{ AFR } \\
\hline \multicolumn{6}{|l|}{ CPA } \\
\hline EEU & 0 & 11 & 15 & 11 & 14 \\
\hline FSU & 0 & 0 & 0 & 0 & 0 \\
\hline \multicolumn{6}{|l|}{ LAM } \\
\hline \multicolumn{6}{|l|}{ MEA } \\
\hline NAM & -12 & 254 & 386 & 277 & 374 \\
\hline PAO & 0 & 19 & 26 & 19 & 25 \\
\hline \multicolumn{6}{|l|}{ PAS } \\
\hline \multicolumn{6}{|l|}{ SAS } \\
\hline WEU & -15 & 80 & 151 & 97 & 146 \\
\hline Total & -27 & 364 & 577 & 404 & 559 \\
\hline
\end{tabular}

Data are presented for the year 2030 by region under different accounting systems, assuming that only Annex I countries participate in the accounting system

Abbreviations: AFR = sub-Saharan Africa, CPA = centrally planned Asia, EEU = Central and Eastern Europe, FSU = Former Soviet Union, LAM = Latin America, MEA = Middle East and North Africa, NAM = North America, PAO = Pacific OECD, $\mathrm{PAS}=$ other Pacific Asia, $\mathrm{SAS}=$ South Asia, WEU = Western Europe.

assuming that non-Annex I countries are responsible for emissions and removals from land use change.

To calculate the emissions from this potential accounting situation, the IPCC and POUR emission estimates from Annex I regions would remain the same as previously calculated. Emissions for nonAnnex I regions would be reduced by the LCA emissions for the production of the biofuels.

In a simple value-chain approach, all emissions along the value chain are the responsibility of the consumer. By including emissions that occur in nations without GHG obligations as well as those due to international transport, value chain approaches can report actual global emissions regardless of whether or not a producing nation has a GHG obligation. However, where a simplistic value chain approach is instituted for bioenergy in nations addressing emissions more generally through a domestic GHG cap, this procedure is prone to double counting. For example, in the case where non-Annex I countries are responsible for emissions from land use change, a simple value-chain approach would double count these emissions.
A solution to this problem has been proposed by DeCicco (2009). He suggests that any emissions that would be reported elsewhere in a GHG accounting system are omitted from the bioenergy value chain. In this accounting scenario, non-Annex I regions are responsible for emissions from land use. These should not be included in the value chain estimate for emissions due to the consumption of biofuels by Annex I regions.

Table 3 show our estimate for the allocation of cumulative emission by region under different accounting systems, assuming that Annex I countries fully participate and non-Annex I countries are responsible for LUC emissions. Since responsibility is being accepted for more emissions than the previous scenario, it is not surprising that the sum across regions is closer to the actual amount.

In this accounting scenario, the DeCicco estimate for non-Annex I regions is essentially the same as in the IPCC accounting approach. For Annex I regions, the estimate of emissions is equal to its emissions from land use change plus a component of all LCA emissions in proportion to the amount of biofuel consumed. 
Table 3. Cumulative emissions caused by biofuels in 2030 by region under different accounting systems

\begin{tabular}{|c|c|c|c|c|c|}
\hline \multirow{2}{*}{ Region } & IPCC & POUR & DeCicco & Tailpipe & Displaced fossil fuels \\
\hline & \multicolumn{5}{|c|}{ All units in $\mathrm{Mt} \mathrm{CO}_{2} \mathrm{eq}$} \\
\hline AFR & 95 & 106 & 95 & & \\
\hline CPA & -34 & 35 & -34 & & \\
\hline EEU & 0 & 11 & 3 & 11 & 14 \\
\hline FSU & 0 & 0 & 0 & 0 & 0 \\
\hline LAM & 695 & 131 & 695 & & \\
\hline MEA & 0 & 22 & 0 & & \\
\hline NAM & -12 & 254 & 60 & 277 & 374 \\
\hline PAO & 0 & 19 & 5 & 19 & 25 \\
\hline PAS & 66 & 66 & 66 & & \\
\hline SAS & -10 & 61 & -10 & & \\
\hline WEU & -15 & 80 & 10 & 97 & 146 \\
\hline Total & 785 & 785 & 890 & 404 & 559 \\
\hline
\end{tabular}

Assuming that Annex I countries fully participate and non-Annex I are responsible for LUC emissions

Abbreviations: AFR = sub-Saharan Africa, CPA = centrally planned Asia, EEU = Central and Eastern Europe, FSU = Former Soviet Union, LAM = Latin America, MEA = Middle East and North Africa, NAM = North America, PAO = Pacific OECD, PAS = Other Pacific Asia, SAS = South Asia, WEU = Western Europe. 


\section{Conclusions}

The goal of Activity 2.1 in the Europe Aid Project 'Bioenergy, sustainability and trade-offs: Can we avoid deforestation while promoting bioenergy?' is to create an improved analysis of the potential of sustainable forest-based bioenergy for climate change mitigation.

To do so we have improved on an existing estimate of land use change and GHG emissions from biofuels by:

- Adding emissions from DWLSOC to the existing emission estimate;

- Adding a sensitivity analysis of emissions to both the assumed DWLSOC carbon stocks and life cycle assessment of the non-LUC emissions;

- Investigating different options for accounting for the emissions from production and combustion of biofuels; and

- Investigating the timing of total GHG emissions from biofuels (production chain and land use change emissions) in comparison to the LCA emissions from fossil fuels by presenting time series rather than cumulative emissions over a given time frame.

It is clear from previous studies (Havlík et al. 2011) that the emissions from biofuels are dominated by the assumed amount of uptake of biofuel from lignocellulosic material. Havlík et al. found that the emissions from biofuels can vary by more than an order of magnitude depending on assumptions about the adoption of technology to create liquid biofuels from cellulosic material (second generation biofuels). This conclusion is beyond the scope of our analysis. Nevertheless, we restate it here so that our conclusions can be viewed with the right perspective.

\section{The importance of dead wood, litter and soil organic carbon}

As pointed out in Bird et al. (2010), including DWLSOC in the estimate of emissions from the adoption of biofuels is important. The significance is directly related to the amount of deforestation predicted by the LUC model. In the GLOBIOM model, the land use change for three biofuel scenarios and a no-biofuels scenario are estimated. The scenarios are:

- No biofuels

- Baseline (60\% first generation and $40 \%$ second generation biofuels);

- First generation only; and

- Second generation only.

In this paper, we have focused on the baseline scenario. Here we found that including DWLSOC increased land use change emissions from biofuel production by $21 \%$ when biofuels are produced on agricultural land. For the first generation scenario, we found that the inclusion of DWLSOC added $16 \%$ to the total emissions. In the second generation scenario, adding DWLSOC increased sequestration by $13 \%$.

\section{Sensitivity to DWLSOC and LCA parameters}

Land use change, from living biomass and DWLSOC, comprises about $80 \%$ of total cumulative emissions from the production of biofuels.

DWLSOC alone accounts for about $15 \%$ of total cumulative emissions. The DWLSOC default values from the IPCC are quite uncertain (usually $\pm 50 \%$ ), and the estimate of total cumulative emissions is quite sensitive to this uncertainty. On the other hand, even though emissions from the non-LUC component are quite substantial, about $25 \%$ of total emissions, the non-LUC parameters are more accurate than the DWLSOC default values. The total cumulative emissions are less sensitive to this uncertainty.

We have documented the sensitivity to DWLSOC and LCA parameters by performing the analysis with low and high DWLSOC parameters. These extremes vary the estimate of total cumulative emissions by $20 \%$. To understand the sensitivity to LCA parameters, we used a Monte Carlo simulation. We found that the estimate of total cumulative emissions from biofuels was rather insensitive to LCA parameters. 


\section{Alternative accounting approaches}

The accounting approach for bioenergy currently adopted by the IPCC and international community does not allocate emissions from the combustion of bioenergy in the energy sector. Rather, emissions from bioenergy are included in the land use sector if the bioenergy causes decreases of carbon stocks. However, there are alternative accounting approaches that should be considered. In Pena et al. (2011), alternative accounting approaches were described and assessed.

As presented in this paper, we find that the IPCC accounting approach:

- Does not properly allocate emissions to the region in which they occur; and

- Very poorly captures the true emissions from the adoption of biofuels if only Annex I countries participate in an accounting target.

The POUR accounting system, on the other hand:

- Properly allocates emissions to the region in which they occur; and
- Captures more, though still not all, of the true emissions from biofuels in a system with partial participation by regions.

The best accounting under partial participation is by value-chain accounting systems.

\section{The importance of considering the timing of emissions rather than just the LCA approach}

Perhaps the most striking result is that emissions from the adoption of biofuels globally in the GLOBIOM 'baseline' scenario (60\% of biofuels are first generation, $40 \%$ second generation) are more than the emissions from fossil fuels that they displace even though bioenergy for an individual action saves emissions in the long term. This result occurs only if one analyses the timing of emissions and not life-cycle emissions. It occurs because every addition of biofuels causes an associated emission with a 'payback' period. However, if the growth of biofuel consumption is large, the year-over-year emissions from biofuels may always be more than from the fossil fuels they are intended to displace. 


\section{References}

Berndes, G., Bird, N., and Cowie, A. 2010.

Bioenergy, land use change and climate change mitigation. IEA Bioenergy Strategic Paper. ExCo:2010:03. http://www.ieabioenergy.com/ LibItem.aspx?id=6770 .

Bird, D.N., Schwaiger, H. and Zanchi, G. 2010

Review of existing methods for carbon accounting. Occasional Paper 54. CIFOR, Bogor, Indonesia.

Carré., F., Hiederer, R. , Blujdea, V. and Koeble, R. 2010 Background guide for the calculation of land carbon stocks in the biofuels sustainability scheme drawing on the 2006 IPCC Guidelines for National Greenhouse Gas Inventories. EUR 24573 EN. Luxembourg: Office for Official Publications of the European Communities. 109p.

Cherubini, F., Bird, D.N., Cowie, A., Jungmeier, G., Schlamadinger, B. and Woess-Gallasch, S. 2009 Energy- and greenhouse gas-based LCA of biofuel and bioenergy systems: key issues, ranges and recommendations. Resources, Conservation and Recycling 53: 434-447.

DeCicco, J. 2009 Addressing biofuel GHG emissions in the context of a fossil-based carbon cap. School of Natural Resources and Environment, University of Michigan, Ann Arbor, MI, USA.

Environmental Protection Agency 2008 Direct emissions from mobile combustion sources. Office of Air and Radiation, Environmental Protection Agency, Washington, DC.

European Union 2009 Directive 2009/28/EC of the European Parliament and of the Council of 23 April 2009 on the promotion of the use of energy from renewable sources and amending and subsequently repealing directives 2001/77/EC and 2003/30/EC. European Union, Brussels.

Fargione, J., Hill, J., Tilman, D., Polasky, S. and Hawthorne, P. 2008 Land clearing and the biofuel carbon debt. Science 319: 1235-1237.

Gibbs, H.K., Johnston, M., Foley, J.A., Holloway, T., Monfreda, C., Ramankutty, N., et al. 2008 Carbon payback times for crop-based biofuel expansion in the tropics: the effects of changing yield and technology. Environmental Resource Letters 3.

Havlík, P., Schneider, U.A., Schmid, E., Böttcher, H., Fritz, S., Skalský, R., et al. [in press] Global land-use implications of first and second generation biofuel targets. Energy Policy.

Hiederer R., Ramos, F., Capitani, C., Koeble, R., Blujdea, V., Gomez, O., Mulligan D. and Marelli, L. 2010 Biofuels: a new methodology to estimate GHG emissions from global land use change. EUR 24483EN. Luxembourg: Office for Official Publications of the European Communities. 150 p.

International Energy Agency 2010 World energy outlook 2010. International Energy Agency, Paris.

Intergovernmental Panel on Climate Change 2003 Good practice guidance for land use, land-use change and forestry. (Penman, J., Gytarsky, M., Hiraishi, T., Krug, T., Kruger, D., Pipatti, R., et al.) Institute for Global Environmental Strategies for the IPCC and IPCC National Greenhouse Gas Inventories Programme, Hayama, Kanagawa, Japan.

Intergovernmental Panel on Climate Change 2006 2006 IPCC guidelines for national greenhouse gas inventories. Volume 4, Agriculture, forestry and other land uses. Institute for Global Environmental Strategies for the IPCC and IPCC National Greenhouse Gas Inventories Programme, Hayama, Kanagawa, Japan.

Pena, N., Bird, D.N. and Zanchi, G. 2011

Development of improved methods for carbon accounting for bioenergy: descriptions and evaluations. Occasional Paper 64. CIFOR, Bogor, Indonesia.

Pingoud, K., Cowie, A., Bird, D.N., Gustavsson, L., Rüter, S., Sathre, R. et al. 2010 Bioenergy: counting on incentives. Science 327: 1199.

Renewable Fuels Agency 2010 Carbon and sustainability reporting within the Renewable Transport Fuel Obligation: technical guidance part two: carbon reporting-default values and fuel chains. Renewable Fuels Agency, London. 
Searchinger, T., Heimlich, R., Houghton, R.A., Dong, F., Elobeid, A., Fabiosa, J. et al. 2008 Use of U.S. croplands for biofuels increases greenhouse gases through emissions from land-use change. Science 319: 1238-1240.
Thrän, D., Sedenberg, T., Zeddies, J. and Offermann, R. 2010 Global biomass potentials: resources, drivers and scenario results. Energy for Sustainable Development 14: 200-205

Wikipedia. Definition of convolution. Accessed 8 March 2011. 


\section{Appendices}

\section{Appendix 1. Sensitivity to land use change scenarios}

The major variation in cumulative emissions is caused by the land use change scenarios that come out of the GLOBIOM model (Havlík et al. 2011). This study developed the land use change events due to four biofuel scenarios using a partial equilibrium economic model. The four biofuel scenarios are:

a. No biofuels;

b. Baseline ( $60 \%$ first generation and $40 \%$ second generation biofuels);

c. First generation only; and

d. Second generation only.

Three options were also evaluated for second generation biofuels. These are created from shortrotation forestry on agricultural land or marginal land or from existing forest lands.
In the main text of our report, the analysis is based on the 'baseline' and 'no biofuels' scenarios. Figure 14 displays the sensitivity of the cumulative emissions from fossil fuels and biofuels to the assumed scenarios. As shown, the cumulative emissions are very sensitive to the scenario. The first generation scenario results in cumulative emissions in 2030 that are almost twice those of fossil fuels (191\%). In the baseline scenario, the focus of the main body of our report, biofuels emissions are $14 \%$ more than those of fossil fuels. Finally, if all biofuels come from second generation processes, the cumulative emissions from biofuels are $12 \%$ of the fossil fuel emissions.

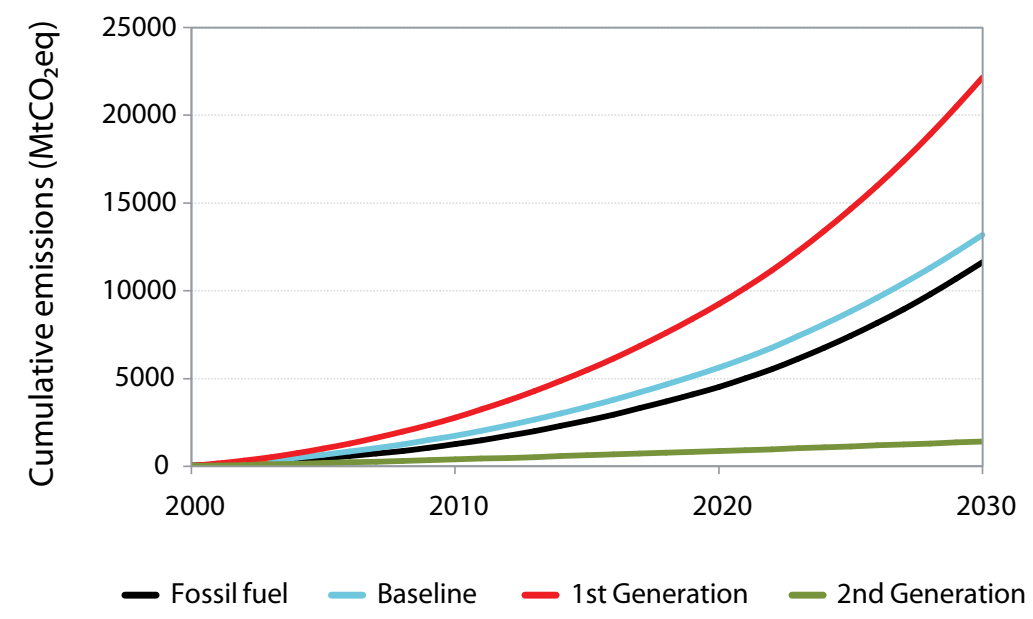

Figure 14. Sensitivity of cumulative emissions from fossil fuels and biofuels with DWLSOC to different scenarios

Source: Havlík et al. (2011) 


\section{Appendix 2. Emission factors for life-cycle emissions from biofuels and fossil fuels}

\begin{tabular}{lccl}
\hline Fuel & $\begin{array}{c}\text { Emissions } \\
(\mathbf{g ~ C O} \text { eq / MJ) }\end{array}$ & $\begin{array}{c}\text { Range } \\
(\%)\end{array}$ & Source \\
\hline Gasoline & 85.0 & \pm 2 & Renewable Fuels Agency (2010) \\
Diesel & 87.6 & \pm 9 & Renewable Fuels Agency (2010) \\
Biodiesel, palm & 54.0 & \pm 35 & European Union (2009) \\
Biodiesel, rape & 46.0 & \pm 35 & European Union (2009) \\
Biodiesel, soy & 50.0 & \pm 35 & European Union (2009) \\
Biodiesel, wood, farmed & 4.0 & \pm 57 & European Union (2009) \\
Ethanol, cane & 24.0 & \pm 20 & European Union (2009) \\
Ethanol, corn & 37.0 & \pm 30 & European Union (2009) \\
Ethanol, wood, farmed & 6.0 & \pm 33 & European Union (2009) \\
\hline
\end{tabular}

Note: Emissions from gasoline and diesel include combustion. Emissions from biodiesel and ethanol do not include combustion or LUC. Ranges are taken from the ranges reported in various LCA studies. The variation may be caused by differences in system boundaries; cultivation practices and crop yields; use of co-products; allocation of emissions to co-products; etc. For more information see Cherubini et al. (2009).

\section{Appendix 3. Combustion emission factors for biofuels and fossil fuels}

\begin{tabular}{lcc}
\hline Fuel & $\begin{array}{c}\text { Emissions } \\
\left(\mathbf{g ~ C O}_{2} \text { eq } / \mathbf{M}\right)\end{array}$ & Source \\
\hline Gasoline & 70.9 & \\
Diesel & 75.4 & \\
Biodiesel & 67.4 & EPA 2008 \\
Ethanol & 62.5 & EPA 2008 \\
\hline
\end{tabular}



This working paper presents an improved analysis of the potential of biofuels for climate change mitigation. It starts from an existing estimate from Havlík et al. (2011) and:

- Adds the emissions from changes in dead wood, litter and soil organic carbon (DWLSOC);

- Includes a sensitivity analysis;

- Investigates different options for carbon accounting; and

- Investigates the timing of emissions from biofuels.

It is clear from Havlík et al. that the greenhouse gas emissions from biofuels are dominated by the future technology. Nevertheless, including DWLSOC in the estimate is important. The significance is directly related to the amount of deforestation predicted. We found that including DWLSOC increased greenhouse gas emissions by 21 per cent. These results are nonetheless sensitive to poorly studied assumptions about DWLSOC dynamics.

The greenhouse gas accounting approach that is currently accepted internationally allocates emissions from bioenergy in the land use sector if a loss of carbon stocks occurs, rather than in the energy sector. As a result, this approach:

- Underestimates the true emissions from biofuels, if few countries participate in a greenhouse gas target; and

- Poorly allocates emissions to the region in which they occur.

We present accounting alternatives which perform these two tasks better.

Finally, greenhouse gas emissions from biofuels can amount to more than from the fossil fuels they displace, even if bioenergy is carbon neutral over the long term. This occurs because every addition of biofuel causes an associated emission with a 'payback' period. If biofuels use grows quickly then the users may continually be emitting more than they are paying back.

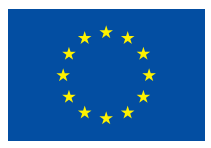
policies and practices that affect forests in developing countries. CIFOR is one of 15 centres within the Consultative Group on International Agricultural Research (CGIAR). CIFOR's headquarters are in Bogor, Indonesia. It also has offices in Asia, Africa and South America. 